\title{
A Review of Acrylamide Neurotoxicity Part II.Experimental Animal Neurotoxicity and Pathologic Mechanisms
}

\author{
PETER S. SPENCER* AND HERBERT H. SCHAUMBURG
}

The companion paper of this review examined the chemical, biochemical and toxicologic properties of acrylamide and its analogues (Spencer and Schaumburg, 1974). Mention was made of the industrial preparation and uses of acrylamide, the hazard faced by industrial workers. and the clinicopathologic features of chronic human acrylamide intoxication.

The present paper summarizes current knowledge of the effects of acrylamide intoxication in laboratory animals. The major focus here is the pattern of nerve damage in experimental acrylamide neuropathy, since this has become the most powerful experimental tool with which to explore human nervous system dying-back disease. Adhering to this theme, the paper concludes with a discussion of the pathologic mechanisms which might be involved in producing the nervous system damage seen in acrylamide neuropathy.

\section{ACUTE INTOXICATION}

Although the experimental peripheral neuropathy produced by chronic low exposure to acrylamide has received most attention, histori-

From the Department of Pathology (Neuropathology), The Saul R. Korey Department of Neurology, and the Rose F. Kennedy Center for Research in Mental Retardation and Human Development, Albert Einstein College of Medicine, The Bronx, New York 10461, U.S.A.

*Joseph P. Kennedy, Jr., Fellow in the Neurosciences.

Reprint requests to Dr. Peter S. Spencer, Dept. of Pathology, Albert Einstein College of Medicine, 1300 Morris Park Ave., Bronx, N.Y. 10461, U.S.A. cally, more interest was generated in the central nervous system signs seen in animals acutely intoxicated with very large amounts of acrylamide. First reported in rats (Druckrey et al., 1953), contemporaneous unpublished studies (Hazleton, 1951-53; Solnitzky, 1953; Kuperman, 1955-56) demonstrated a sequence of clinical findings in dogs, cats, mice, rats, rabbits and frogs intoxicated with $100-5,000 \mathrm{mg} / \mathrm{kg}$ of acrylamide. The LD.50 in rodents is $170 \mathrm{mg} / \mathrm{kg}$ (Stockinger, 1956). Clinical signs are not seen before 15 minutes, regardless of the amount or route of administration of acrylamide. Gradually, over a period of minutes or hours, depending on the route of administration and the dose, neurologic and circulatory manifestations become apparent. These include hypotension, postural and motor incoordination, hindlimb ataxia, generalized tremulousness, behavioral changes, a massive sympathetic discharge and culminate in recurrent tonic-clonic convulsions (Kuperman, 1957; 1958). Death may result, probably from respiratory failure due to laryngeal spasm and obstruction (Riker, 1954). Using EEG recordings from acutely. intoxicated spinal decerebellate, decerebrate and decorticate cats, Kupperman (1958) stated convulsive doses of acrylamide produced high voltage and hypersynchronous electrical cortical activity. He concluded acrylamide could produce a sustained and intense EEG seizure only in the presence of an intact brainstem.

The clinical signs of acute acrylamide poisoning have been confirmed by subsequent investigators
(Barnes, 1969b; 1970; Fullerton and Barnes, 1966) but convulsions have not been demonstrated in acutelyintoxicated primates (McCollister et al., 1964). If animals survive the effects of acute poisoning, recovery may be rapid and complete (Barnes, 1969; Fullerton and Barnes, 1966; Riker, 1954). For example, we found cats were convulsive 24 hours after $100 \mathrm{mg} / \mathrm{kg}$ acrylamide but had totally recovered one day later.

\section{CHRONIC INTOXICATION}

Chronic acrylamide intoxication of experimental animals produces a neurologic picture predominantly of peripheral neuropathy. In recent years, great interest has been engendered in experimental acrylamide neuropathy, since it serves as an animal model of human peripheral neuropathy in which bilateral symptoms and signs initially appear distally and slowly progress proximally. Such neuropathies, whether produced by acrylamide, other neurotoxic chemicals, such as cresyl phosphates (Cavanagh, 1963) or nutritional disorders (Cavanagh, 1964) collectively are characterized as dying-back polyneuropathies.

Experimental acrylamide neuropathy, first produced in the Hazleton laboratories (Hazleton, 1951-53) and reported by American Cyanamid Company (1952), has been investigated clinically (Barnes, 1970; Chenoweth, 1955-56; Fullerton, 1969; Hamblin, 1956; Hopkins, 1968, 1970; Hopkins and Gilliatt, 1967; Kaplan and Murphy 1972a; Kaplan et al., 1973; Kuperman, 1955-56, 1957, 1958; Leswing and Ribelin, 1969; McCollister et al., 1964; Riker, 1954; Schaumburg et al., 
1973, 1974), histologically (Bradley and Asbury, 1970; Fullerton and Barnes, 1966; Hashimoto and Ando, 1973; Hopkins, 1968, 1970; Kaplan et al, 1973; Leswing and Ribelin, 1969; Morgan-Hughes et al., 1974; Ribelin, 1964) and ultrastructurally (Ghetti et al., 1973; Kocen and Thomas, 1971; Ochoa and Morgan - Hughes, 1974; Prineas, 1969b; Schaumburg et al., 1973; Schaumburg et al., 1974; Suzuki and De Paul, 1973; Suzuki and Pfaff, 1973; Tsujihata et al., 1974). Electrophysiologic (Fullerton and Barnes, 1966; Hopkins, 1968; Hopkins and Gilliatt, 1971; Hopkins and Lambert, 1972; Leswing and Ribelin, 1969; Sumner, 1973; Sumner and Asbury, 1974; Swift and Lambert, 1974), biochemical (Asbury et al., 1973; Hashimoto and Aldridge. 1970; Hashimoto and Ando, 1971, 1973; Kaplan and Murphy, 1972; Kuperman, 1957) and studies of axonal transport (Bradley and Williams, 1973; Pleasure et al., 1969) have been conducted during various stages of neuropathy induced by acrylamide intoxication.

\section{CLINICAL STUDIES}

Acrylamide neuropathy has been produced in all mammals studied. Primates (Leswing and Ribelin, 1969; McCollister et al., 1964) and guinea-pigs (Ribelin, 1964; West, 1959) are more resistant than cats or rodents. Susceptibility to acrylamide is higher in older animals (Barnes, 1969a, b, Fullerton and Barnes, 1966; Kaplan and Murphy, 1972b; Kaplan et al., 1973) although suckling rats are also vulnerable (Sukuki and Pfaff, 1973). Male and female animals react similarly (Fullerton and Barnes, 1966). Acrylamide neuropathy is more readily induced after bilateral adrenalectomy, delayed by pre-treatment with DDT or phenobarbitone, but animals are not more susceptible in pyridoxine or thiamine deficiency states (Kaplan and Murphy, 1972a \& b). Concurrent administration of methionine and acrylamide reduces the neurotoxic potency of acrylamide (Hashimoto and Ando, 1971). If the initial daily doses of acrylamide are

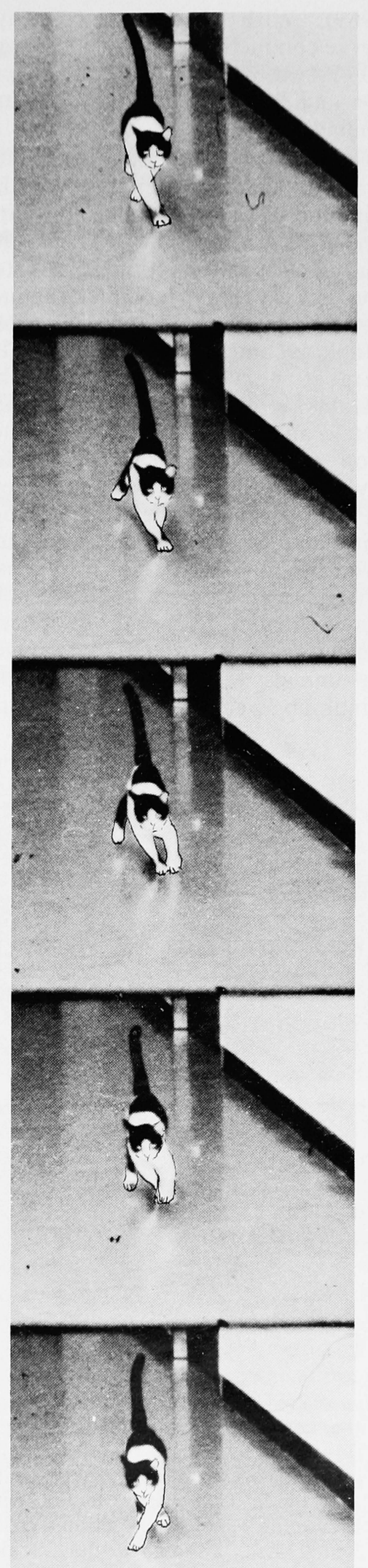

extremely low $(0.3-1 \mathrm{mg} / \mathrm{kg}$ for cats and $1-3 \mathrm{mg} / \mathrm{kg}$ for monkeys), no neurologic signs are detected after one year of intoxication (McCollister et al., 1964).

Peripheral neuropathy is readily induced in animals by repetitive dosing with aqueous solutions of acrylamide (eg. $10-50 \mathrm{mg} / \mathrm{kg} /$ day) irrespective of the route (Hamblin, 1956; Kuperman, 1957, 1958), including dermal applications (McCollister et al., 1964). Hindlimb signs appear first; by two weeks in suckling rats receiving $50 \mathrm{mg} / \mathrm{kg}$ intraperitoneally daily for 6 days (Suzuki and Pfaff, 1973), and by 40-100 days in baboons eating fruit containing $10 \mathrm{mg} / \mathrm{kg} / \mathrm{day}$ (Hopkins, 1968, 1970). Onset of signs is more rapid in cats receiving $20 \mathrm{mg} / \mathrm{kg} /$ day (4-6 days) compared with the same species receiving half of this daily dose (13-15 days). Proprioceptive sense impairment is considered by some to be one of the first signs and is seen before hindlimb paralysis (Bradley and Asbury, 1970; Hamblin, 1956; McCollister et al., 1964). Tendon reflexes are lost both in upper and lower extremities (Hopkins, 1970). In cats, we found (Schaumburg et al., 1974) hindlimb unsteadiness is an early feature and this progresses into a gross truncal ataxia with crossing of forelimbs and hindlimb splay (Fig. 1). Tremor and head titubation are sometimes present during the maintenance of posture. With continued intoxication, animals become progressively unsteady in the lower extremities, and eventually are forced to drag themselves about using their forelimbs. Animals receiving smaller amounts of acrylamide develop symptoms later and progress insidiously. We demonstrated quadraparesis after eight and a half months in cats receiving $3 \mathrm{mg} / \mathrm{kg} /$ day. Forelimb signs

Figure 1 - Retouched movie sequence of an ataxic cat chronicallyintoxicated with acrylamide. As the cat walks, there is a broad-based hindlimb placement, crossing forelimbs and a truncal sway. (Figure 1, Schaumburg et al., 1974, reproduced by permission). 
occur after hindlimb signs; in baboons, this is first seen as clumsiness and loss of grip (Hopkins, 1968, 1970) and in cats as foot-drop (Prineas, 1969b). Facial muscles may become involved if intoxication is extended for long periods of time (Hopkins, 1970). Hoarseness and weight loss (Leswing and Ribelin, 1969; Prineas, 1969b; Riker, 1954) and normal (Kuperman, 1957) or poor growth (McCollister et al., 1964) and have been reported. Significantly, reaction to painful stimuli is preserved throughout the illness, even when animals are paralysed (Hopkins, 1968, 1970; Leswing and Ribelin, 1969), although Sumner (1974) reported blunted sensation in cats' paws after severe intoxication. Cessation of acrylamide dosing is followed by recovery, initially rapid (Leswing and Ribelin, 1969; Hopkins, 1970; McCollister et al., 1964) although the speed of recovery depends on the age of the animal (Barnes, 1969a; Kaplan and Murphy, 1972b) and degree of intoxication. Cats recovering from prolonged insidious intoxication, which produced severe ataxia followed by quadraparesis, display a residual ataxia (see also Fullerton and Barnes, 1966) or, almost no neurologic deficit after 10 months. However, recovered animals are more vulnerable to re-dosing with acrylamide (Stokinger, 1956), requiring approximately half the original amount of acrylamide to reprecipitate ataxia (Kuperman, 1957). In rats, the greater vulnerability to redosing with acrylamide eventually disappears. Return of normal sensitivity corresponds to a return of the normal level of sciatic nerve $B$-glucuronidase activity which increases significantly during administration of acrylamide (Kaplan and Murphy, 1972b).

\section{ELECTROPHYSIOLOGIC STUDIES}

Animals exposed to acrylamide for short periods show no abnormalities but a small reduction in nerve conduction velocity and amplitude is evident when clinical symptoms are mild (Leswing and Ribelin,
1969). With severe neuropathy, nerve conduction velocity is reduced $20-49 \%$ in the distal regions (Fullerton and Barnes, 1966; Hopkins and Gilliatt, 1971).

Reduction in conduction velocity is more marked in nerves of the hindlimb than the forelimb (Leswing and Ribelin, 1969) and both velocity and amplitude reduction are greater for sensory nerve conduction than motor conduction (Hopkins, 1968; Hopkins and Gilliatt, 1971). The largest nerve fibers show the greatest reduction in response amplitude and the reduction in conduction velocity may be accounted for by a loss of large diameter fibers (Fullerton and Barnes, 1966; Hopkins and Gilliatt, 1971). Correlated with the maintenance of pain sensitivity, conduction characteristics of unmyelinated axons in peripheral and autonomic nerves are unchanged in animals with marked fore- and hindlimb weakness (Honkins and

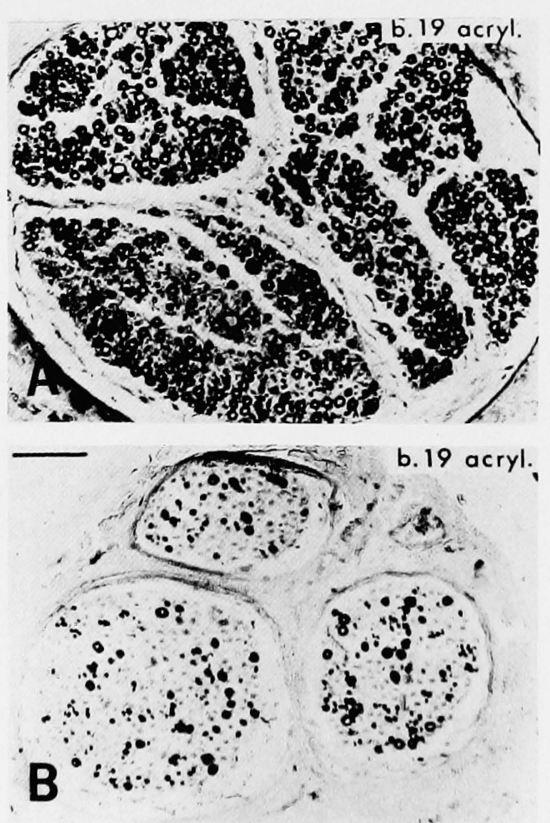

Figure 2 - A (upper), cross-section of the nerve to biceps femoris and $B$ (lower), the nerve to the extensor digitorum brevis in a baboon with acrylamide neuropathy. Fixed with Flemming's solution, stained with Kultschitsky's hemotoxylin. Scale: $100 \mu \mathrm{m}$. (Figure 48, Hopkins 1968 and figure 4, Hopkins, 1970; reproduced by permission).
Lambert, 1972). Sumner (1973) and Sumner and Asbury (1974) have found that IA afferent nerve fibers from primary spindle terminals display greater abnormalities of conduction than group II fibers. By contrast, motor nerve fibers are among the most resistant in acrylamide-poisoned animals (Sumner and Asbury, 1974).

When paralyzed animals are allowed to recover by withdrawing acrylamide, conduction velocity in previously unaffected nerves may first deteriorate, then show substantial improvement (Hopkins and Gilliatt, 1971; Leswing and Ribelin, $1969)$ or return to the normal range of values (Fullerton and Barnes, 1966). Recovery in the forelimb is more rapid than in the hindlimb, and sensory nerve action potentials return more slowly than motor function. During regeneration, there is a dispersion of the muscle response and a lower amplitude response to proximal stimulation than to distal stimuli (Hopkins and Gilliatt, 1971).

\section{MORPHOLOGIC STUDIES}

In experimental acrylamide neuropathy, the major lesion occurs in the distal parts of peripheral nerves with progression of the damage centripetally. Ribelin (1964) first identified a lesion in the sciatic nerves of intoxicated animals. Fullerton and Barnes (1966) and Hopkins $(1968,1970)$ systematically studied the nerve fiber damage using paraffin sections and teased nerve fibers. They demonstrated that distal parts of nerves are more severely affected than proximal parts (Fig. 2 ). The lesion was characterized by a loss of nerve fibers. Degenerating fibers frequently were encountered distally but occasionally they were seen in both spinal nerve roots (Fullerton and Barnes, 1966; Prineas, 1969b). Fullerton and Barnes (1966) indicated medium to large diameter fibers $(8-9 u \mathrm{~m})$ are most susceptible to degeneration in the rat but Hopkins and Gilliatt (1971) stated the largest and longest fibers $(10-16 \mu \mathrm{m})$ of both motor and sensory nerves degenerated first in the baboon, quoting the large fiber drop-out seen 

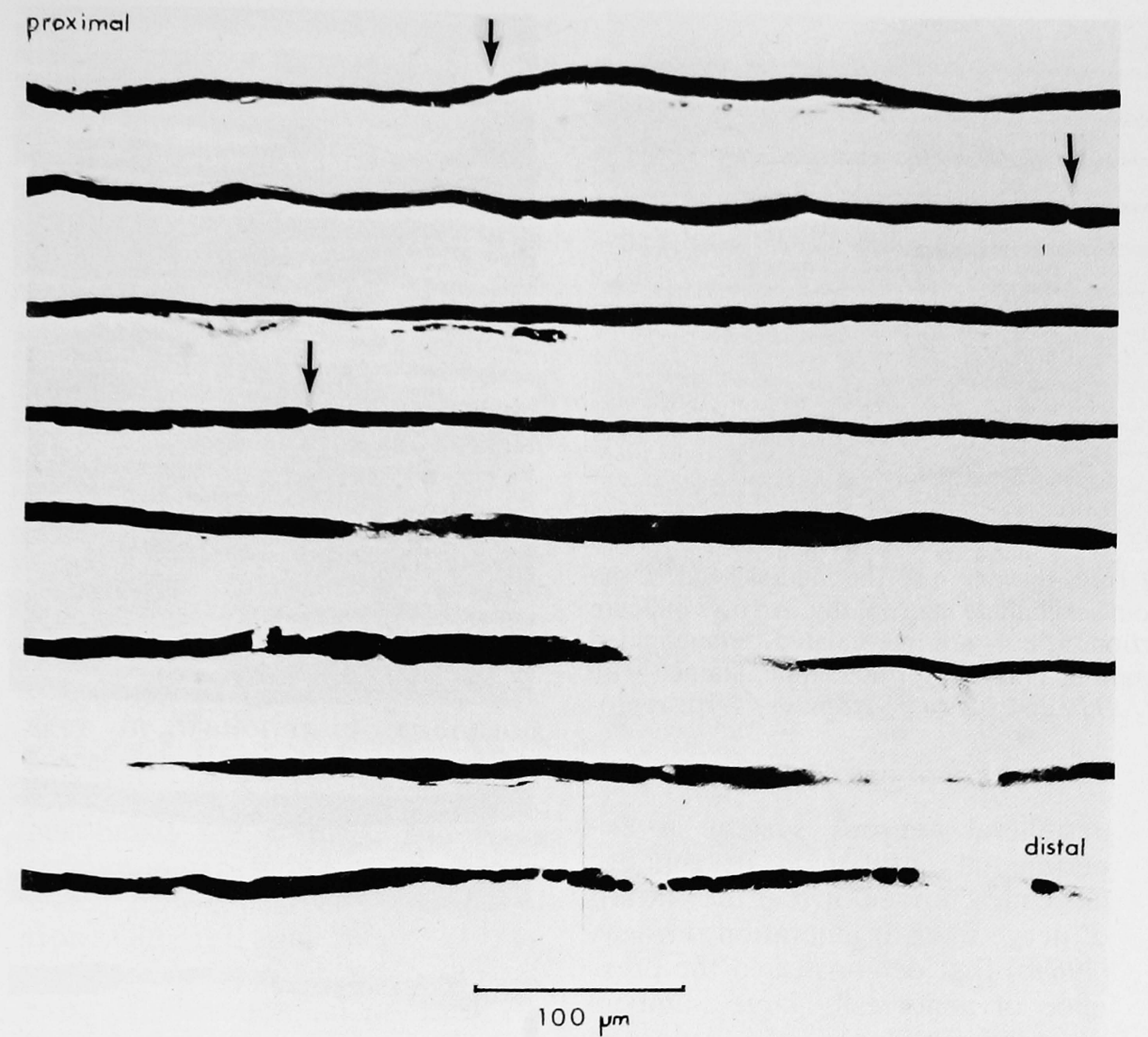

Figure 3 - Single teased myelinated fiber from the nerve to extensor digitorum brevis of a baboon with acrylamide neuropathy. Successive lengths of the fiber are mounted below each other; toward the distal region, the fiber is disintegrating. Arrows indicate preserved nodes. Fixed in formol-saline, stained with osmium tetroxide. (Figure 54, Hopkins, 1968 and figure 6, Hopkins, 1970; reproduced by permission).

in a sural nerve of one patient biopsied by Fullerton (1969) as further evidence. With prolonged intoxication, myelinated fibers of all sizes are affected (Hopkins and Lambert, 1972) but unmyelinated fibers are relatively resistant (Schaumburg et al., 1974). Individual teased nerve fibers from the sural nerves of the neuropathic baboons reflected the dying back process by displaying progressively more severe changes distally with relative preservation proximally (Fig. 3). Suzuki and Pfaff (1973) noted axon degeneration in distal portions of nerves was most severe around blood vessels. Concurrent with axon degeneration and secondary myelin breakdown, there is an appearance of endoneurial macrophages and a proliferation of Schwann cells (Bradley and Ashbury, 1970; Suzuki and Pfaff, 1973). many of the fine structural features of axonal growth cones apparently arrested because of the effects of the acrylamide intoxication (Ochoa and Morgan-Hughes, (1974). On the other hand, Aguayo and PrysePhillips (1974) found normal regeneration of unmyelinated axons in crushed cervical sympathetic trunks and sural nerves of acrylamidepoisoned rats.

Teased fiber studies also revealed some fibers with short remyelinated segments in propinquity to the posi-

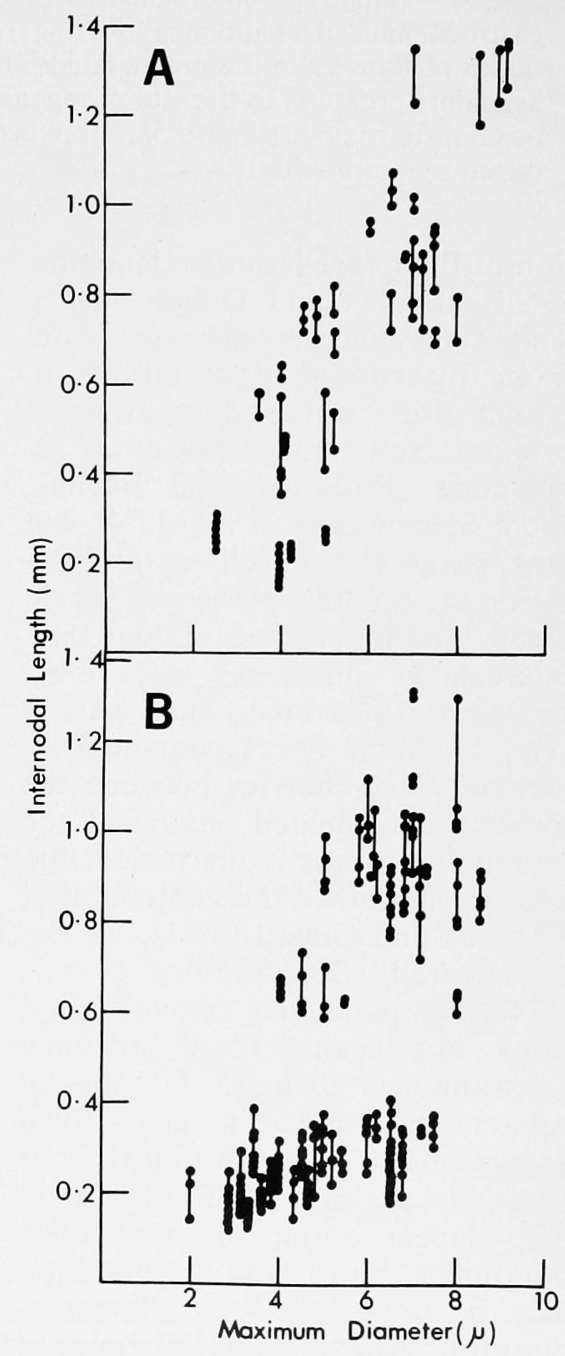

Figure 4 - A (upper), internodal length and fiber diameter relationships in the posterior tibial nerve of normal rats and B (lower), pooled data from two rats recovering from acrylamide neuropathy. (Figure 10, Fullerton and Barnes, 1966, reproduced by permission) 


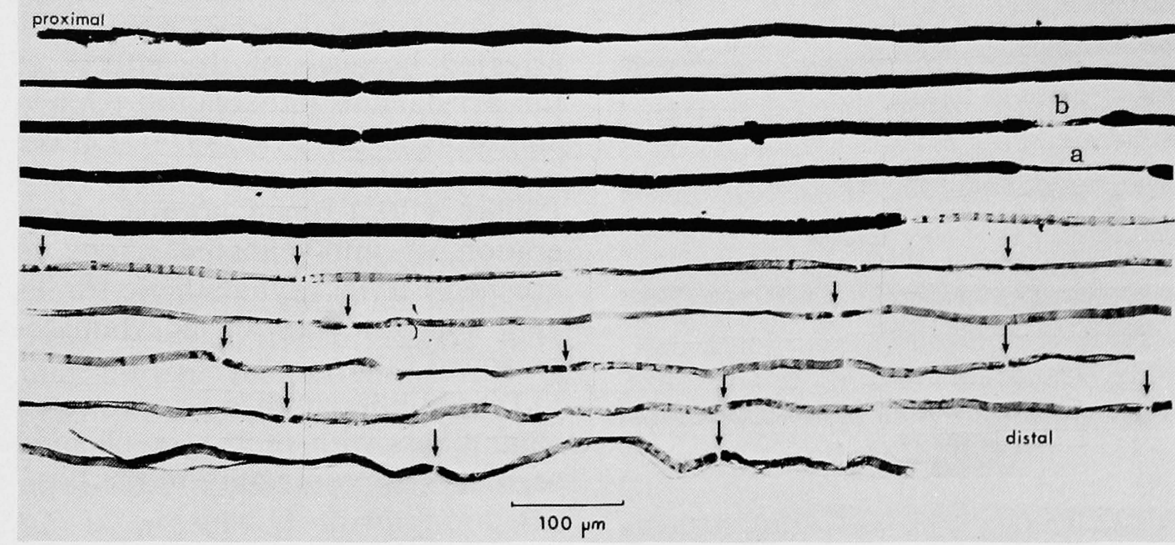

Figure 5 - Single teased myelinated fiber from the nerve to the medial head of the gastrocnemius of a baboon recovering from acrylamide neuropathy. Arrows indicate nodes of Ranvier in the regenerated portion. a, b - are intercalated, remyelinated segments proximal to the site of regeneration. Fixed in formol-saline, stained with osmium tetroxide. (Figure 56, Hopkins, 1968 and figure 7, Hopkins, 1970: reproduced by permission).

tion of fiber regeneration (Hopkins, 1968; Hopkins and Gilliatt, 1971). This remyelination did not result from internodal demyelination, which does not accompany the primary axon damage caused by acrylamide (Fullerton and Barnes, 1966; Schaumburg et al., 1974), but was paranodal in character. Between the terminal preserved myelinated internodes, one or two thin, intercalated internodes were present, shorter proximally than distally (Fig. 5). Some fibers contained intact nodes of Ranvier between the focally remyelinated sites and the terminal preserved internode (Fig. 6A). In support of the contention of Hopkins and Gilliatt (1971), we demonstrated (Schaumburg et al., 1974) that paranodal demyelination does not result from primary Schwann cell damage, but myelin retracts in response to gross focal enlargement predominantly of paranodal axons (Fig. 6B). The axon may appear normal in contiguous internodes but frank degeneration may be present a few millimeters distally. These nodal/paranodal changes appeared to be an early, potentially reversible feature of axon change which heralded forthcoming degeneration in adjacent internodes if intoxication was maintained (Schaumburg et al., 1974).

Ultrastructural study of the peripheral nervous system in experimental acrylamide neuropathy has characterized further the pattern of nerve fiber degeneration. Prineas (1969b) first demonstrated the presence of abnormally large numbers of neurofilaments and enlarged mitochondria in myelinated nerve fibers of cats with neuropathy, a finding later confirmed by Suzuki and Pfaff (1973). Focal axon neurofilamentous hyperplasia has now been identified in other toxic neuropathies such as that produced by inhalation of hexane (Asbury, 1974) and methyl n-butyl ketone (Spencer et al., 1974).

In acrylamide neuropathy, the neurofilamentous accumulations initially occur at paranodal regions (Fig. 7A) where they appear to cause local axon swelling (Fig. 7B) leading to the paranodal retraction of myelin observed by light microscopy (Fig. 6A). In these swollen portions of the axon, there are abnormally large numbers of axonal dense bodies, mitochondria, multivesicular bodies and small vesicles, but neurotubules are rare. Free and membrane-bound granules may also be prominent. Groups of abnormal organelles near Schmidt-Lanterman clefts and at paranodes frequently are surrounded by complex, membranous profiles derived from adaxonal Schwann cell cytoplasm surrounded
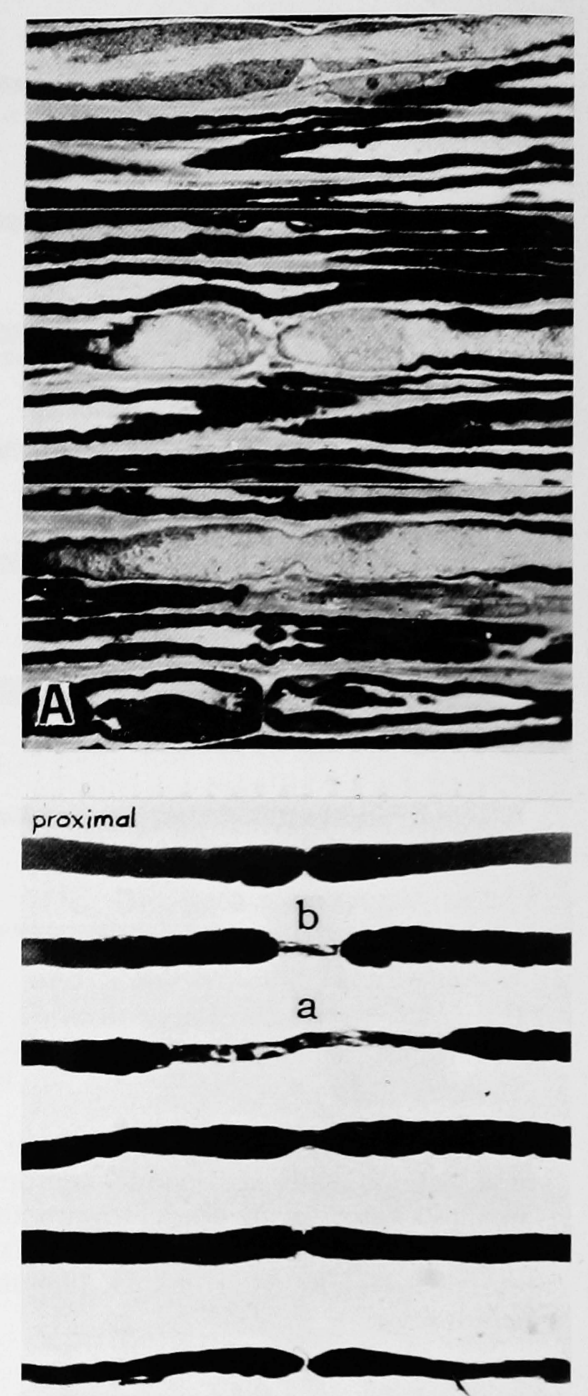

distal

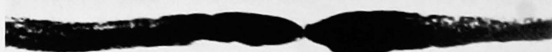

B $100 \mathrm{\mu m}$

Figure 6 - A (upper three). Massive axonal swellings near nodes of Ranvier associated with paranodal myelin retraction. Fibers sited in the tibial nerve above the ankle of a cat with acrylamide neuropathy. Fixed with glutaraldehyde followed by osmium tetroxide; $1 \mu \mathrm{m}$ epon sections, stained with toluidine blue. Each X620. B (lowest), successive paranodal regions on a single fiber from the pudendal nerve of of a baboon recovering from acrylamide neuropathy. a, b - are intercalated remyelinated internodes. Fixed in formol-saline, stained with osmium tetroxide. (Figure 59, Hopkins, 1968, and figure 12, Gilliatt, 1969; reproduced by permission). 
by axolemma (Fig. 8A). Spencer (1971) and Spencer and Thomas (1975) have suggested these profiles represent an attempt by the Schwann cell to sequester and remove abnormal organelles from the axon. They are encountered proximal to the level of frank fiber disruption and characteristically form a honeycomb array (Fig. 8B). Although these profiles are occasionally seen in normal nerve fibers, their numbers increase dramatically in many axonal neuropathies and, as such, they are useful indicators of early axonal compromise. As the axon becomes further impaired in acrylamide intoxication, the fiber breaks up with the formation of ovoids indistinguishable from those seen in Wallerian degeneration. Local Schwann cell division occurs (Bradley and Asbury, 1970), Büngner bands are formed, and these receive regenerating axon sprouts which may appear during intoxication (Suzuki and Pfaff, 1973). Acrylamide-induced unmyelinated axon degeneration has not been observed (Aguayo and Pryse-Phillips, 1974; Schaumburg et al., 1974).

Schaumburg et al. (1974) determined the spatio-temporal pattern of distal peripheral nerve, sensory and and motor nerve terminal axon degeneration in the paws of cats intoxicated with acrylamide. This study demonstrated some sensory nerve terminals were more vulnerable than motor nerve terminals. Pacinian corpuscle axons in fore- and hindfeet were the first terminals to display axonal changes. Sometimes accompanied by neurofilamentous hyperplasia, the first change was a loss of characteristic axonal processes (Spencer and Schaumburg, 1973) from the surfaces of ultraterminal (Fig. 9A) and terminal axons. Ocasionally, groups of enlarged degenerating mitochondria were phagocytosed by the surrounding inner core cells. Clear spaces developed beneath the axolemma (Fig. 9B) and eventually the axolemma was lost leaving a clump of extracellular axoplasm which gradually disappeared. The preterminal fiber portion displayed concurrent axonal
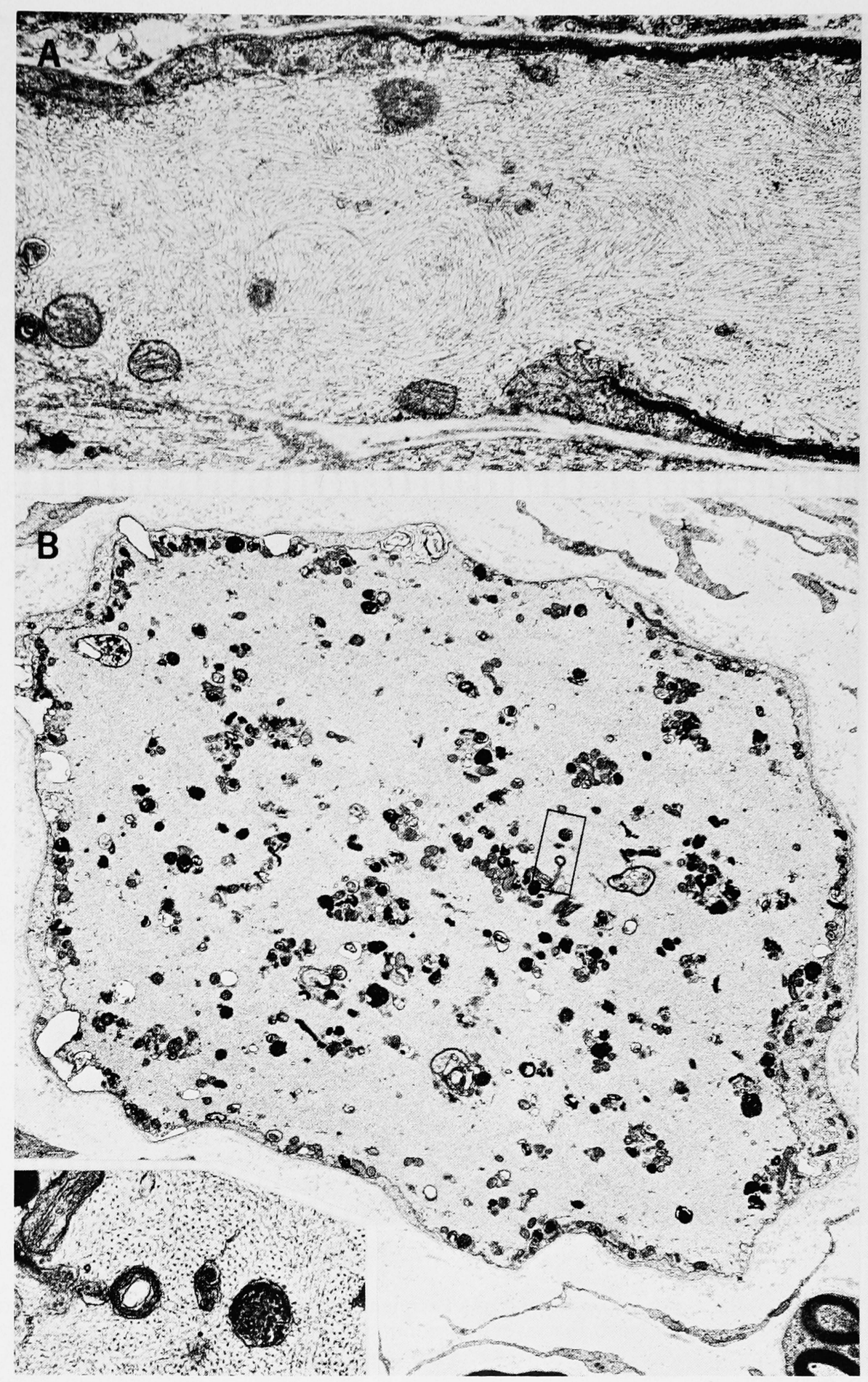

Figure 7 - A (upper). Sciatic nerve fiber of a suckling rat intoxicated with acrylamide, prior to evidence of hindlimb weakness. The axon is filled with neurofilaments and a very few neurotubles. This figure and figures 8-11 are micrographs of tissues fixed with glutaraldehyde followed by osmium tetroxide, and stained with uranyl acetate followed by lead citrate. X 20,250. (Figure 9A, Suzuki and Pfaff, 1973, reproduced by permission).

B (lower). Cross-section of an abnormally large fiber profile, probably a demyelinated paranodal region similar to those illustrated in Figure 6A. X 8,400. (Figure 3, Schaumburg et al., 1974; reproduced by permission). Inset, shows the boxed portion in $\mathrm{B}$ at a higher magnification: X 42,000. 

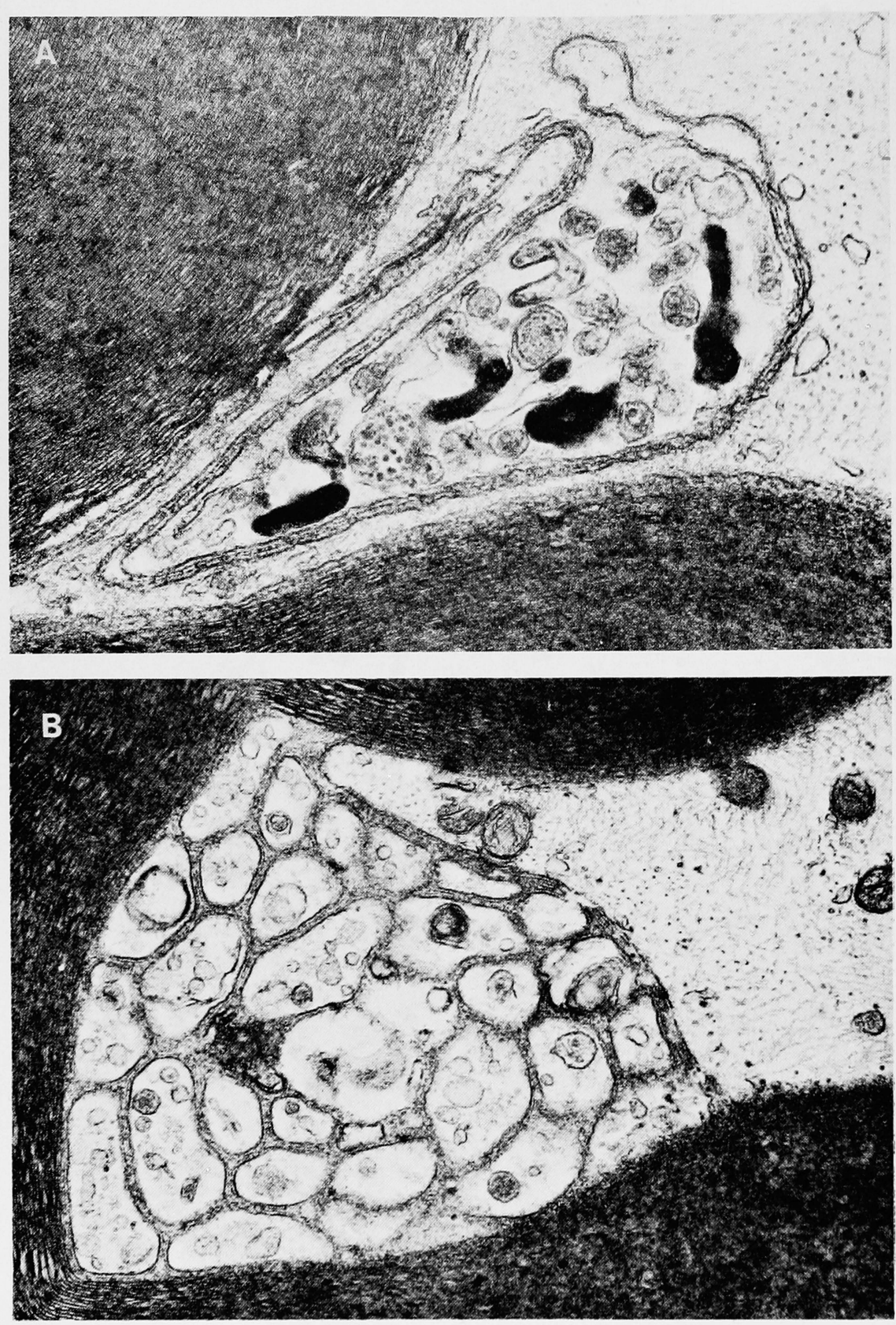

$\leftarrow$ Figure 8 - A (upper). Adaxonal Schwann cell invagination into the axon compartment which has sequestered a group of abnormal axonal organelles. Tibial nerve above the ankle of a cat with acrylamide neuropathy. X 27,000.

B (lower). Multiple adaxonal invaginations together form a complex profile in the axon compartment of a myelinated nerve fiber, and compartmentalize abnormal organelles derived from the axoplasm (Spencer, 1971). X 19,000. (Figure 13, Prineas, 1969b, reproduced by permission).

changes which were sometimes more severe proximally than distally (Figs. 9C and 9D). Eventually, corpuscles became totally denervated (Fig. 10) and reinnervated on recovery.

Degeneration of primary annulospiral endings of muscle spindles began shortly after changes were first seen in juxtaposed Pacinian corpuscle axons (Schaumburg et al., 1974). The large IA fibers supplying the primary endings underwent frank breakdown before the secondary nerve terminals, supplied by smaller group II fibers, displayed axonal change. Secondary and primary terminals (Fig. 11A) underwent neurofilamentous accumulation (Fig. 11B) and later disappeared. In one muscle spindle, which displayed annulospiral nerve terminals filled with neurofilaments, the primary IA axon contained a massively swollen paranodal region proximally (Fig. 12A). The 5 nodes of Ranvier which intervened between the focal swelling and the neurofilament-filled terminals were normal in histologic appearance

Figure 9- Inset (top left). Diagram of a Pacinian corpuscle showing the single, preterminal myelinated fiber (P-T); as it enters the center of the corpuscle, the myelin discontinues and the axon forms the naked terminal region (T) which ends in a bulbous ultraterminal zone (U-T). A-D refer to the other figures of the plate to indicate the levels from which they were cut.

A-D. Skip-serial cross-sections from a single Pacinian corpuscle removed from the hindpaw of a chronically-intoxicated cat, prior to the appearance of clinical signs.

A - ultraterminal axon containing increased numbers of neurofilaments and lacking characteristic, microfilament-filled filopod processes described by Spencer and Schaumburg (1973); the shape and position of axonal processes in a normal corpuscle is indicated diagramatically. X 6,500 .

$\mathrm{B}$ - terminal region has lost its characteristic polar filopod processes and displays non-artefactual clear spaces beneath the axolemma. X 13,500 .

$\mathrm{C}$ - preterminal fiber, sectioned paranodally, displays focal axonal neurofilamentous hyperplasia and dense body accumulation. $X 9,000$.

$\mathrm{D}$ - preterminal fiber, proximal to $\mathrm{C}$, illustrating the more advanced axonal degeneration at this position. $\mathrm{X} 5,400$. At $\mathrm{E}$ in diagram at top left, the fiber appeared similar to $\mathrm{C}$. 


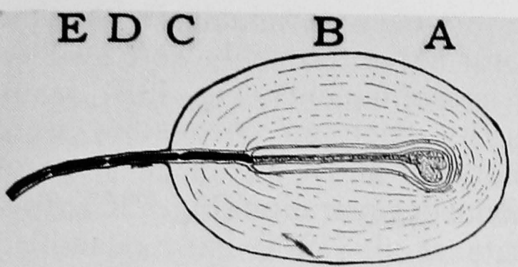

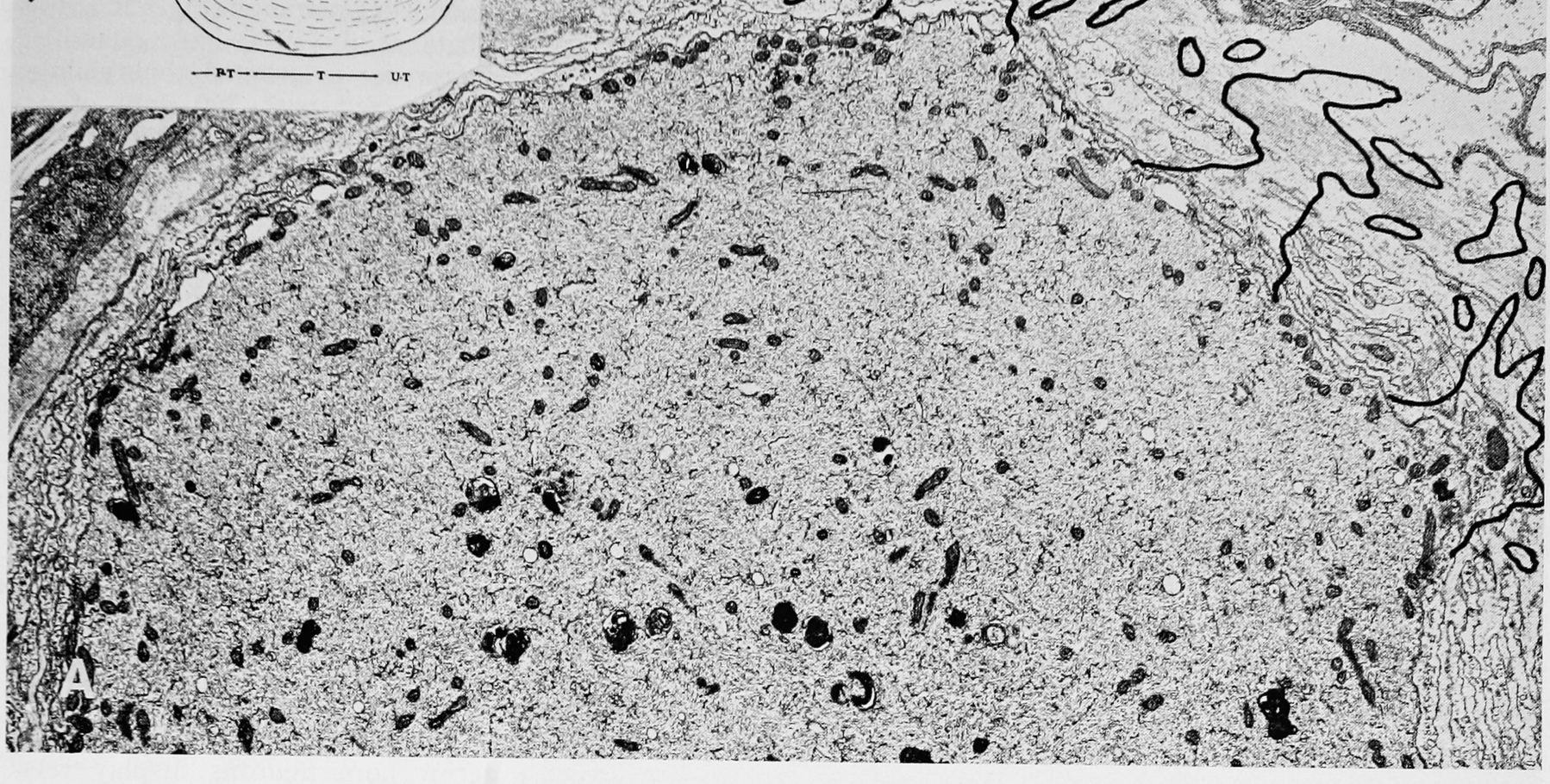

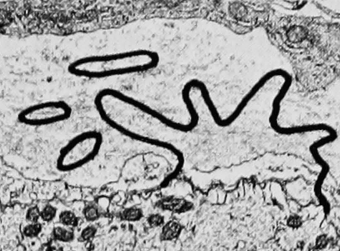

(2)

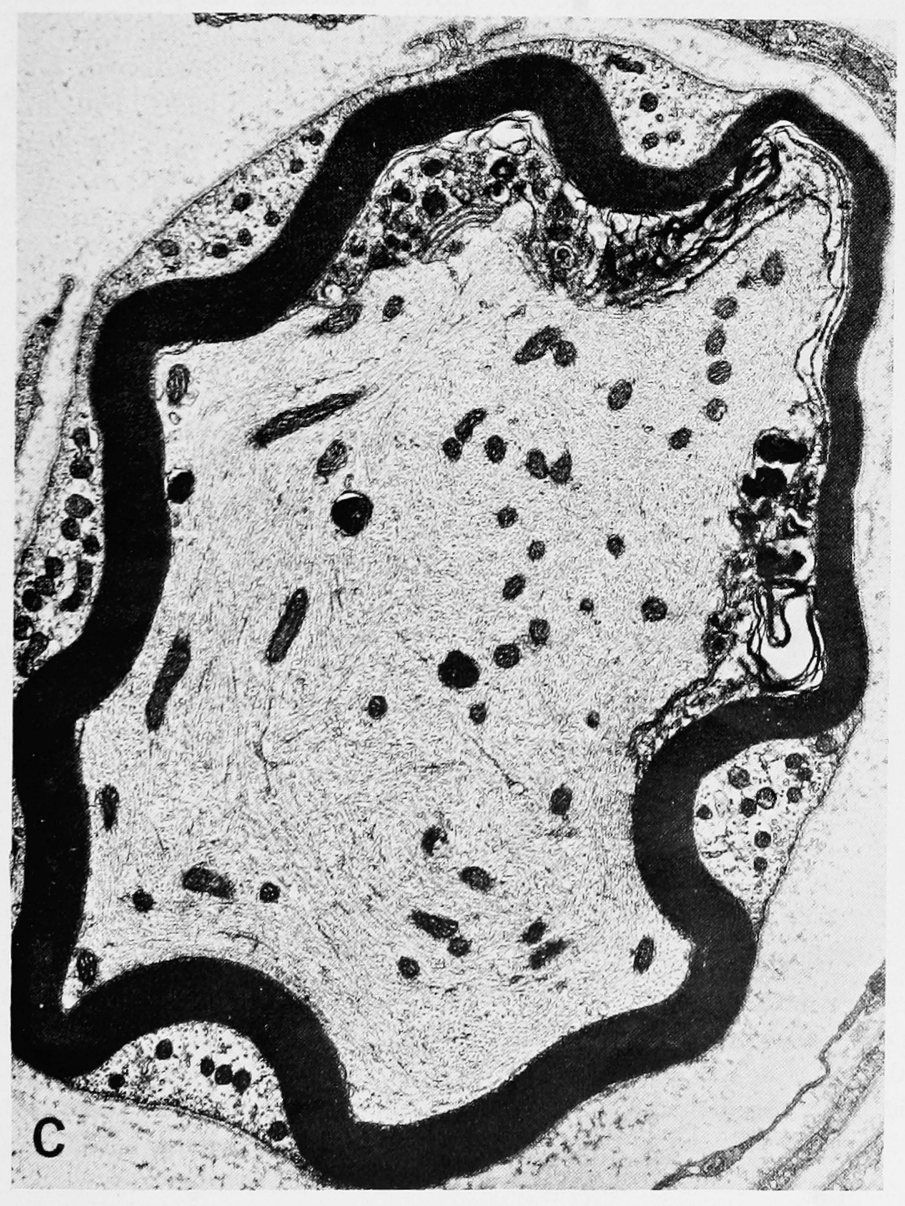

ans.

1) 19

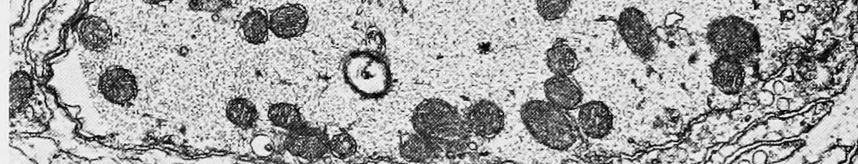

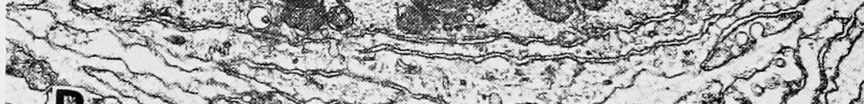

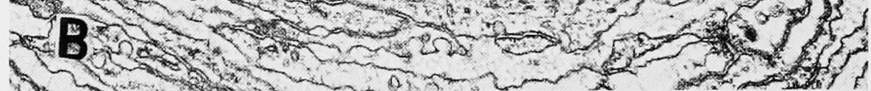

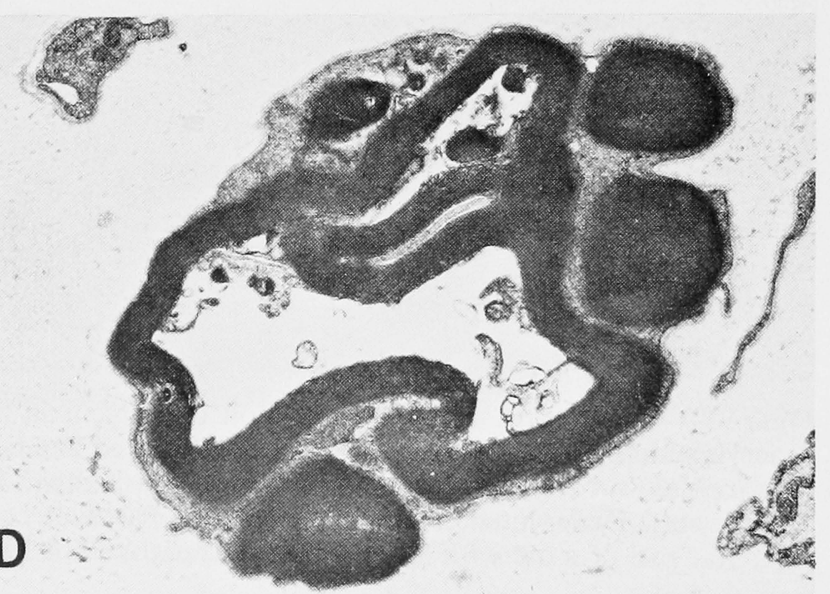


(Fig. 12B). Axons supplying Golgi tendons organs in the hindfeet of cats also degenerated (Lig. 13A).

Although Prineas (1969b) and Tsujihata et al. (1974) called attention to the early changes in motor nerve terminals supplying extrafusal muscle fibers, Schaumburg et al. (1974) found these terminals were considerably less vulnerable than adjacent
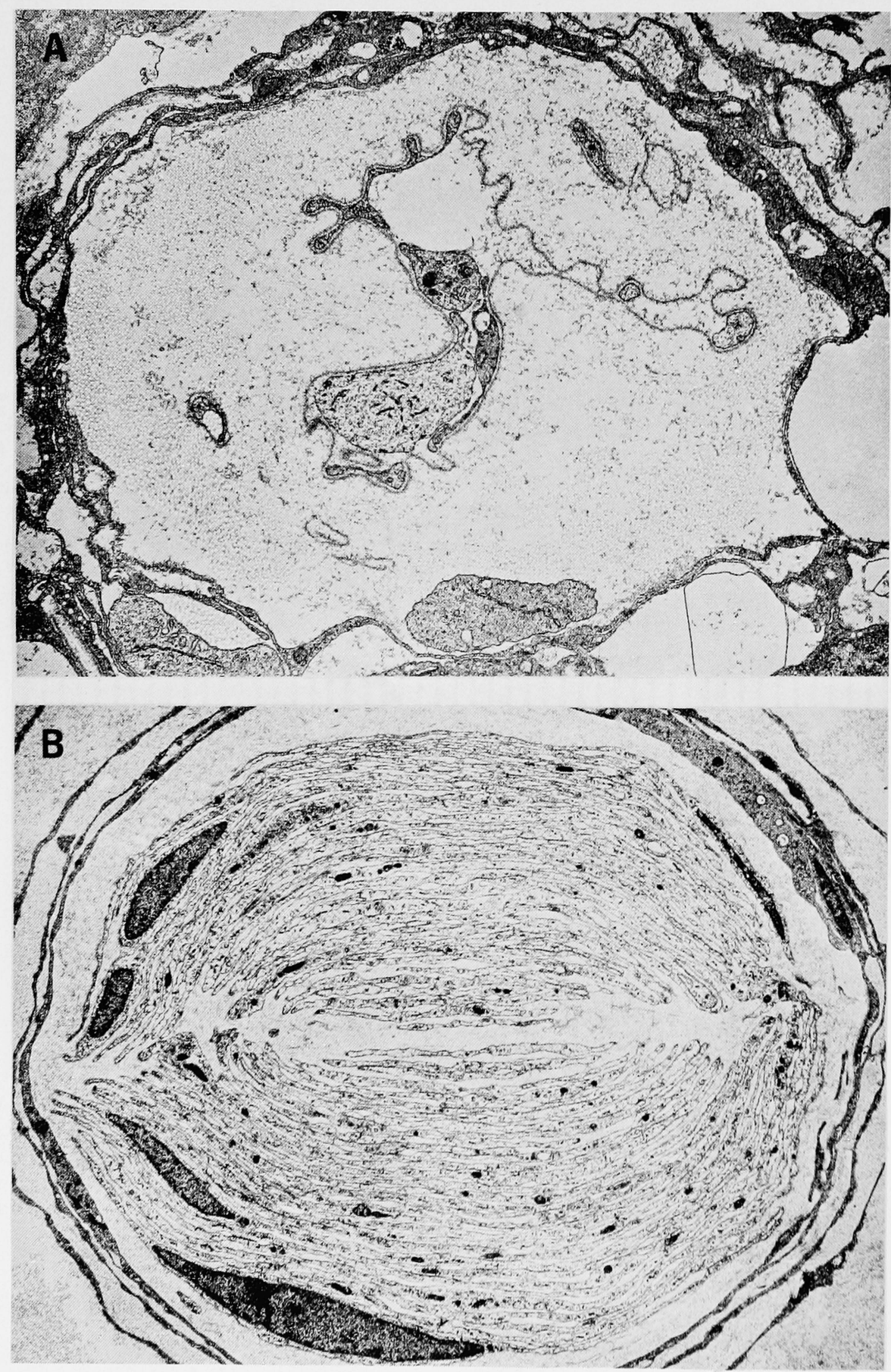

Figure 10- A (upper). Preterminal region of a Pacinian corpuscle from a cat with acrylamide neuropathy. The fiber has degenerated and is replaced by Schwann cell processes surrounded by a collapsed basement lamina. X 8,000.

$B$ (lower). Denervated terminal region of a Pacinian corpuscle from the forefoot plantar pad of a cat with acrylamide neuropathy. X 4,300.

sensory nerve terminals. By the time motor nerve terminals were swollen by neurofilaments (Fig. 13B), many nearby Pacinian corpuscles were empty or at an advanced stage of axonal degeneration (Fig. 13C). Tsujihata et al. (1974) have quantified motor nerve terminal abnormalities in rats fed with $300 \mathrm{ppm}$ of acrylamide. Synaptic number per unit area was reduced $17-31 \%$ by 20 days in terminals swollen threefold by neurofilament accumulation (Fig. 14A). Swift and Lambert (1974) found a decreased pool of acetylcholine quanta immediately releasable from nerve terminals in similarly treated rats. Eventually, motor nerve terminals disappear leaving denuded endplates (Fig. 14B). Muscle fibers fail to grow normally and, after denervation, atrophy may ensue. The pattern of distal peripheral nerve degeneration and regeneration during and after intoxication with acrylamide is summarized diagrammatically in figure 15 .

Dorsal root ganglion cells and anterior horn neurons display relatively few abnormalities in experimental acrylamide neuropathy (Bradley and Asbury, 1970; Fullerton and Barnes, 1966; McCollister et al., 1964; Suzuki and Pfaff, 1973). Prineas (1969b) demonstrated there was some loss of the normal parallel arrangement of ribosome-studded endoplasmic reticulum and possibly a numerical increase of mitochondria, but numbers of neurotubules and neurofilaments were normal. Evidence of central chromatolysis has not been seen despite the presence of distal axonal degeneration (Bradley and Asbury, 1970) but can be produced after a local crush is applied to a nerve of an intoxicated animal (Bradley and Asbury, 1970; Prineas, 1969b). Dorsal roots however, contain enlarged mitochondria (Fig. 16) and may display neurofilamentous hyperplasia with similar changes in distal nerve twigs (Prineas, 1969b).

Central nervous system pathology has recently been recognized in cats chronically intoxicated with acrylamide. In the spinal cord, Prineas (1969b) found degenerating fibers in 
the anterior and lateral columns but not in the posterior columns when peripheral nerve fiber damage was evident in distal nerves. Neurofilamentous whorls were present in boutons terminaux in the anterior spinal gray matter at the $\mathrm{S} 1$ level. At cervical levels in advanced disease, changes were pronounced in the gracile nucleus. Small myelinated fibers displayed neurofilamentous hyperplasia, mitochondria, dense body and fine granular material plus unusual branched tubulo - vesicular profiles (Ghetti et al., 1973; Prineas, 1969b). Myelin disintegration was rarely observed, as were axonal abnormalities in large myelinated fibers (Prineas, 1969b). Huge, nonmyelinated axonal profiles, containing masses of neurofilaments and many dense bodies were seen synapsing with dendrites of the neurons of the gracilis nucleus. Similar changes were not seen in the fibers terminating in the cuneate nucleus (Figs. 17, 18) although changes have been seen in this nucleus in intoxicated rats (Suzuki and Pfaff, 1973). Neurons of the gracilis neucleus show only minor changes early in the neuropathy (Ghetti et al., 1973; Prineas, 1969b), but with prolonged exposure to acrylamide, these neurons may display prominent abnormalities (Ghetti et al., 1973). Animals having recovered from a neurologic deficit associated with abnormalities in gracilis axon terminals, possess normal terminals after recovery. Recovery from severe neurologic illness is associated with an apparent reduction in the number of gracilis axon terminals and a proliferation of astroglial cell processes. Abnormal neurons also are seen at this time (Ghetti, 1973).

There is sparse information on other central nervous system pathology in acrylamide neuropathy, Ghetti et al. (1973) have demonstrated neurofilamentous hyperplasia and many mitochondria in the mossy endings of the rostral cerebellar vermis (Fig. 19) and Prineas (1969b) showed extensive fiber destruction of the the dorsal spinocerebellar tracts in the medulla of cats. Kuperman's (1958) suggestion that acrylamide damaged the midbrain has not been investigated.

\section{PATHOLOGIC MECHANISMS}

Three pathologic mechanisms have been proposed to account for the dying-back pattern of nerve fiber damage produced by chronic acrylamide intoxication. One theory suggests that neuron perikaryal metabolism is compromised; a second that the axonal transport system is impaired, while the third concept considers that acrylamide exerts a direct, toxic effect on the axon, without impairing axonal transport.

\section{NEURON PERIKARYAL IMPAIRMENT}

One hypothesis to account for the distal and slow centripetal axonal degeneration produced by chronic acrylamide intoxication, considers that acrylamide directly or indirectly interferes with neuron perikaryal metabolism, resulting in a gradual decrease in the production of materials required for the maintenance of axonal integrity. The extremities of axons would suffer first from a lack of essential materials produced by neuronal perikarya since more proximal regions would be supplied
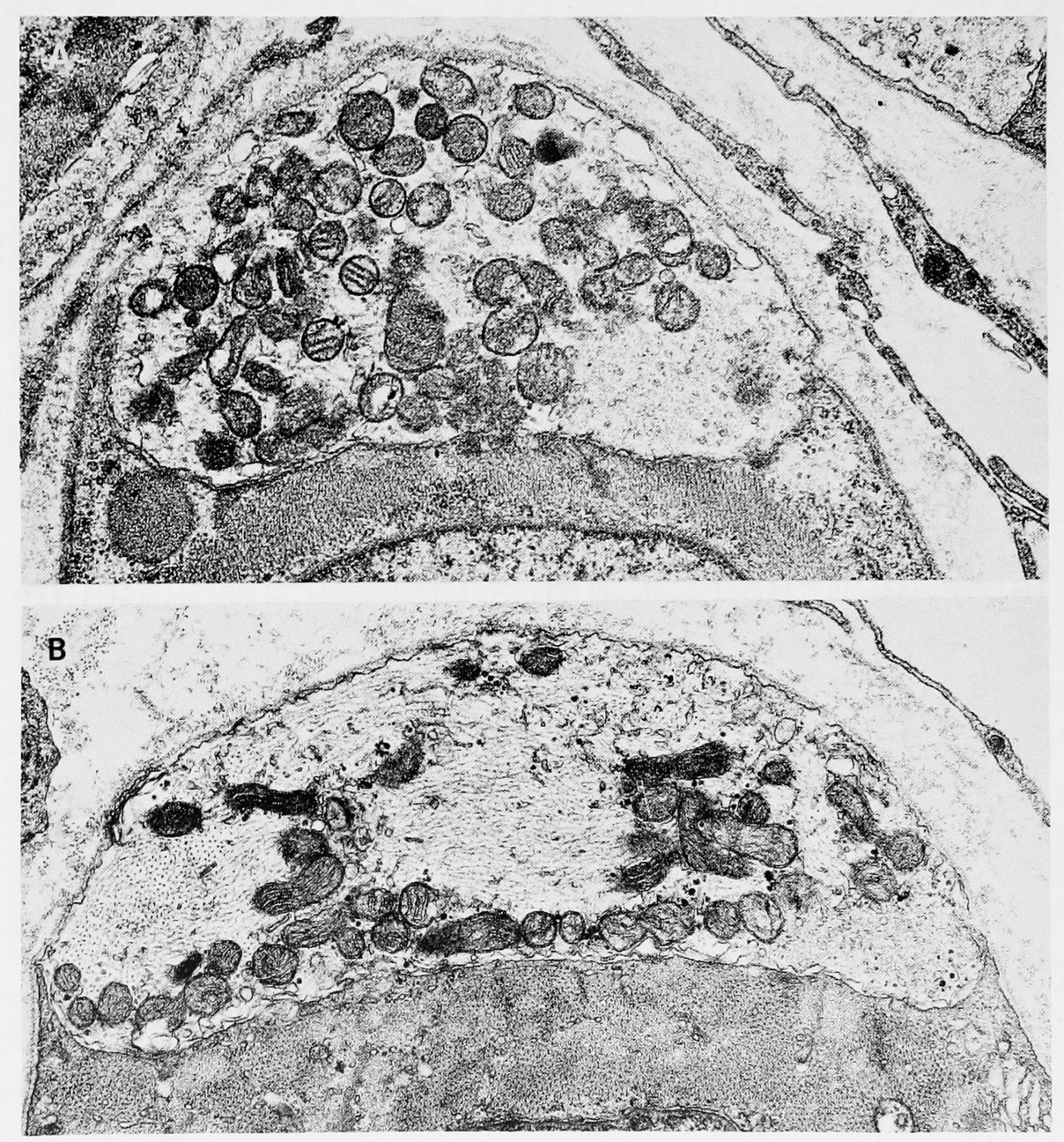

Figure 11 - A (upper). Section of an annulospiral ending from the equatorial region of a nuclear chain intrafusal fiber in the lumbrical muscle of a normal cat. X 20,000. B (upper). Similar region to A from an ataxic cat chronically intoxicated with acrylamide. Note the large number of neurofilaments. X 22,500. 

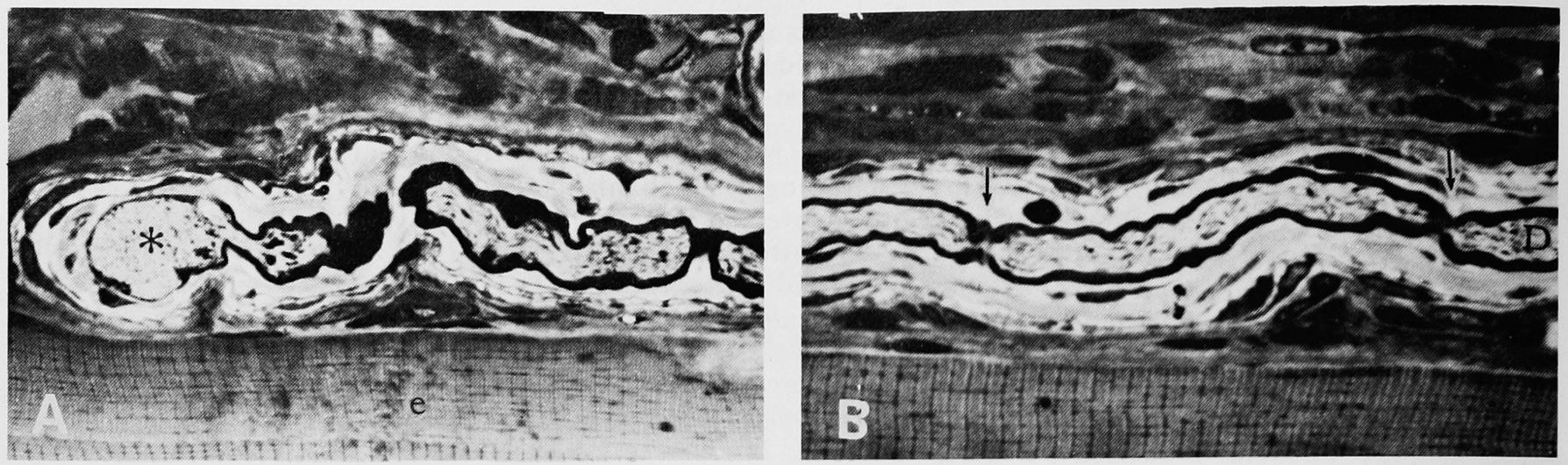

Figure 12 - A (left) and B (right). Contiguous sections of the IA myelinated nerve fiber supplying primary terminal illustrated in figure 11B which was sited approximately three internodes distal (D) to the extreme right portion of the fiber. One proximal paranodal region displays marked swelling $(*)$ while more distal nodes $\rightarrow$ appear normal. X 560. e- extrafusal muscle fiber. This figure and figure 13 are light micrographs of tissue fixed with glutaraldehyde followed by osmium tetroxide; $1 \mu \mathrm{m}$ epon sections, stained with toluidine blue.
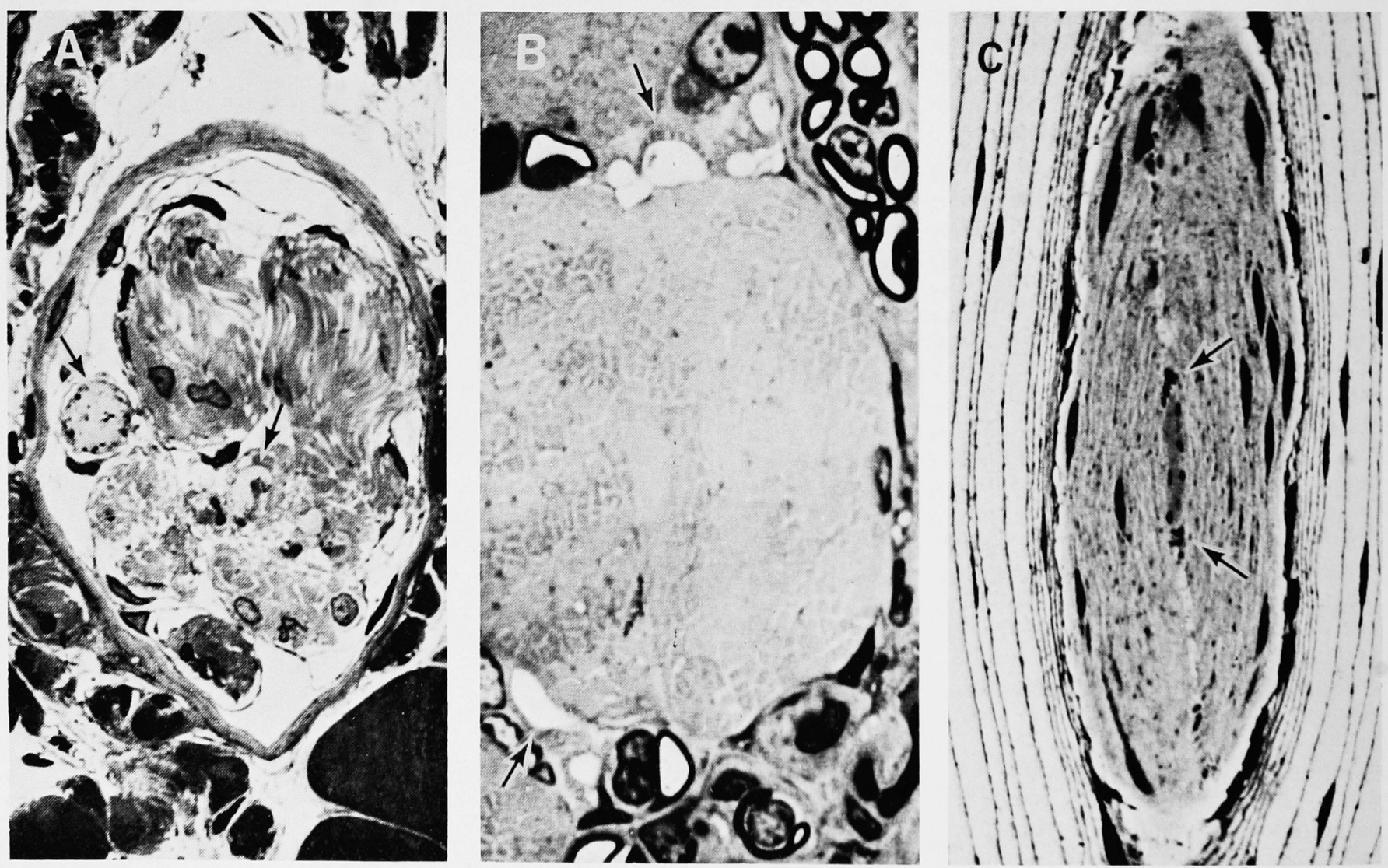

Figure 13 - A (left). Swollen axonal profiles $\rightarrow$ in a Golgi tendon organ from the hindfoot of a cat chronically-intoxicated with acrylamide. X 760 .

$\mathrm{B}$ (center). Early change (swelling) of motor nerve terminals (arrows) supplying extrafusal muscle fibers in the lumbrical muscle of a cat with acrylamide neuropathy. X 1,720.

$\mathrm{C}$ (right). Advanced changes in the terminal region of a corpuscle sampled close to the muscle illustrated in B. Ultrastructurally, the axon had lost its axolemma (see also figure 10, Schaumburg et al., 1974) and axoplasmic organelles had been phagocytosed by inner core cell processes (arrows) (see also figure 9, Schaumburg et al., 1974). X 1,600. 

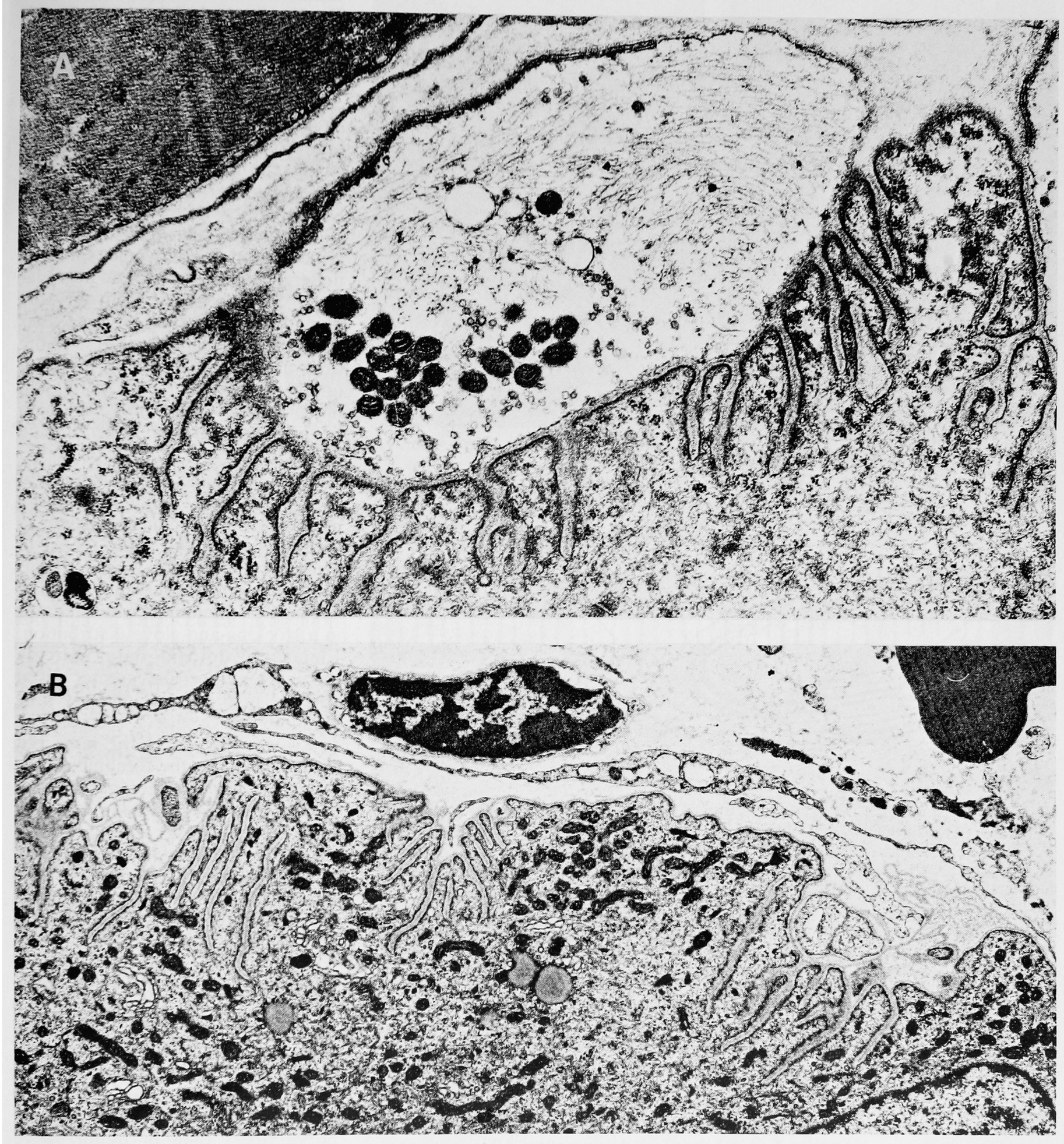

Figure 14 - A (upper). Motor nerve terminals from the hindfoot of a cat with acrylamide neuropathy. The axon contains an abnormally large number of neurofilaments and sparse synaptic visicles. This figure and B are electron micrographs of tissue fixed with glutaraldehyde followed by osmium tetroxide and stained with uranyl acetate followed by lead cetrate. X 23,000

$\mathrm{B}$ (lower). Denervated motor endplate in a lumbrical muscle of a cat with severe acrylamide neuropathy. X 9,600 . 

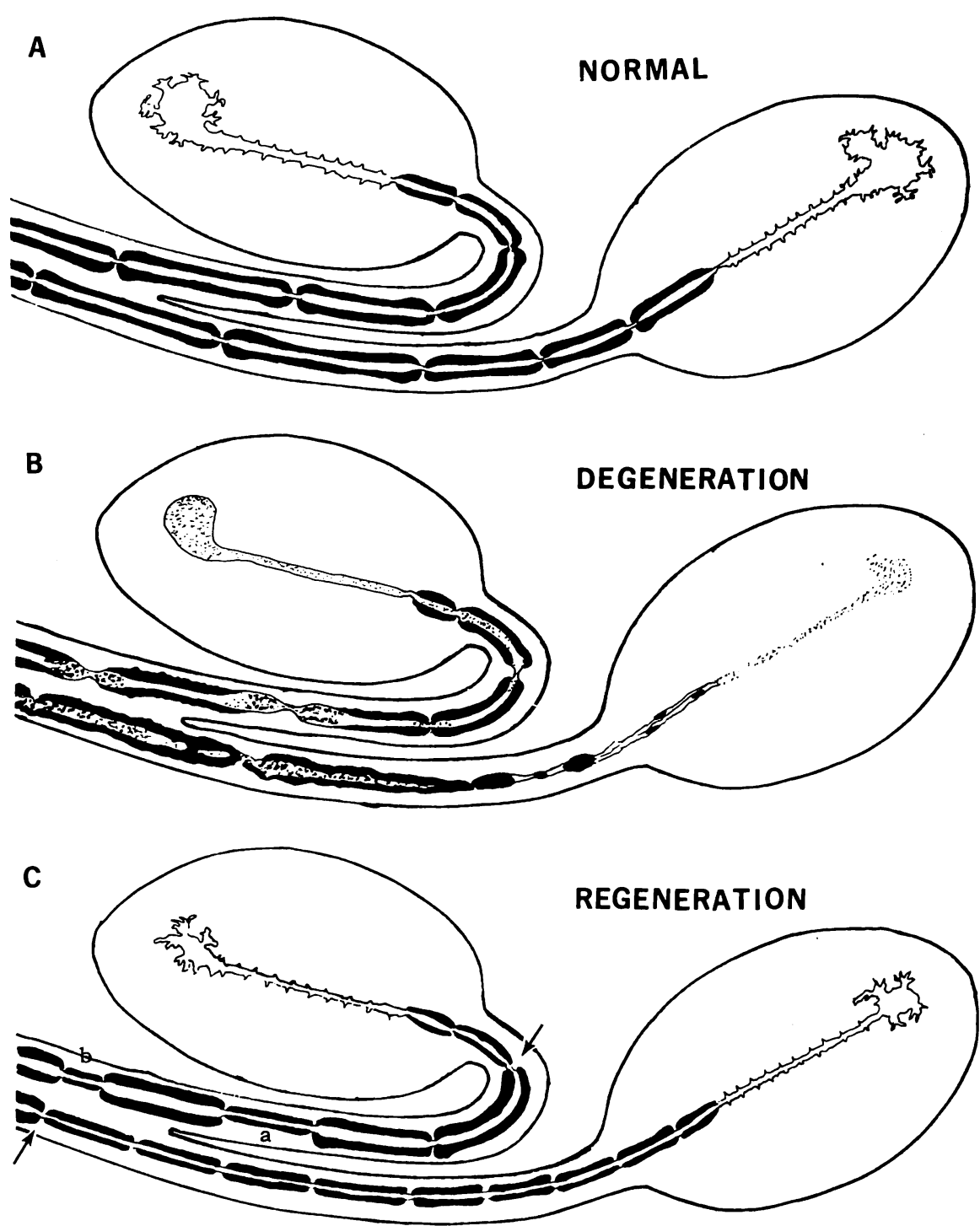

Figure 15 - Diagram to indicate the pattern of change in distal peripheral nerve fibers before (A), during (B) and after (C) acrylamide intoxication, using Pacinian corpuscle fibers as examples.

A (upper). Normal Pacinian corpuscle fibers display short internodes preterminally, and the terminal and ultraterminal portions contain numerous branching filopod axonal processes.

B (center). Shortly after repetitive dosing with acrylamide, the terminal and ultraterminal zones contain increased numbers of neurofilaments and filopod processes are absent (left). More proximally, the same fiber displays paranodal axonal swelling and myelin retraction. Affected proximal paranodes display less myelin retraction than affected distal paranodes. More distal paranodes may be unaffected. In a more severly affected adjacent corpuscle (right), the terminal and ultraterminal axons are represented by clumps of extracellular neurofilaments and residual degenerating mitochondria. The preterminal axon has degenerated, and proximal paranodal axonal disease has spread to involve entire internodes leading to fiber disintegration.

C (lower). During recovery, both fibers regenerate from the proximal limit of degeneration $\rightarrow$ forming short, thinly myelinated internodes. After entering the corpuscle, the regenerating axon reestablishes relationship with the inner core. Regions which display paranodal axonal swelling and myelin retraction, but which did not progress to overt disintegration, have reconstituted and formed short, intercalated internodes, shorter proximally (b) than distally (a). first. In addition, it is assumed acrylamide disturbs the metabolic process of all nerve cells, but the degree of disturbance is such as to impair first the survival of those axons with the greatest demand for perikaryal supplies (Cavanagh, 1964, 1969). Thus, axonal degeneration would commence at the distal tips of the largest and longest axons, with a temporal, seriate progression of change proximally pari passu with increasing perikaryal impairment. Subsequently, extremities of both shorter and smaller axons would be affected and these would similarly undergo a slow, centripetal degradation. The proximal limit of this dying-back process in any one fiber would then be dependent first on the fiber diameter and length, and secondly, on the degree of perikaryal impairment, which would vary with the level and duration of acrylamide intoxication.

In many respects, the features of the human and animal neuropathy produced by acrylamide harmonize with the predictions of this theory of progressive perikaryal impairment. Signs and symptoms frequently first occur in the hindlimbs and forelimbs in a stocking-and-glove distribution. Electrophysiologic data indicate there are earlier and greater distal changes in the large and very long hindlimb nerve fibers than in the equivalent regions of the large but shorter fibers in the forelimbs, with concurrent preservation of the proximal portions of nerves in both extremities. However, recent ultrastructural studies of experimental acrylamide neuropathy have indicated the pattern of pathology is more complex than was apparent by light microscopy. The earliest ultrastructural abnormality is seen in some distal sensory nerve terminals before the change can be detected in adjacent motor nerve terminals. This correlates both with the clinical finding of early sensory deficit, and the proportionately greater and earlier impairment of conduction of sensory nerve fibers than of motor nerve fibers. Of the nerve terminals examined in the hindfeet of acrylamide-intoxicated cats, the hierarchy of terminal vulnerability 
Figure 16 - A (left). Cross-section of the ventral root of a cat with acrylamide neuropathy. Mitochondria within the axoplasm of both large and small fibers are of normal size. $\mathrm{X}$ 3,500 .

B (right). By contrast, dorsal root axons contain enlarged mitochondria, especially evident in large fibers. Fixed in glutaraldehyde followed by osmium tetroxide; stained with uranyl acetate followed by lead citrate. X 3,500. (Figures 17 and 18, Prineas, 1969 b; reproduced by permission).

determined by Schaumburg et al (1974) was: Pacinian corpuscle $>$ muscle spindle primary afferent $\gg$ extrafusal motor nerve terminal. Although this sequence of distal axon degeneration cannot be explained on the basis of decreasing nerve fiber diameter, it may be reasoned from the theory of perikaryal impairment, that the singular sensitivity of Pacinian corpuscle axons results from their dorsal root ganglion cell perikarya each having to supply a peripheral axon and in addition, a long central projection to the gracile nucleus, where axonal degeneration has also been observed. Antithetically, the later onset of axonal degeneration in juxtaposed motor nerve terminals could be correlated with the smaller volume of

Figure 17 - A (left). Primary input axon terminals in the gracilis nucleus of a cat intoxicated with $220 \mathrm{mg} / \mathrm{kg}$ of acrylamide over a period of 3 weeks. One abnormal terminal ( $\mathrm{t}$ ) is in synaptic contact with a dendritic process (d) of normal appearance. X 10,000. (Courtesy of Dr. B. Ghetti).

$\mathrm{B}$ (right). Swollen terminal axon (a) in the gracilis nucleus of a cat intoxicated for 18 days with a total of $340 \mathrm{mg} / \mathrm{kg}$ of acrylamide. In addition to the many neurofilaments, the axon contains numerous dense membranous bodies and many mitochondria. Fixed in glutaraldehyde followed by osmium tetroxide; stained with uranyl acetate followed by lead citrate. X 13,000. (Courtesy of Dr. B. Ghetti).
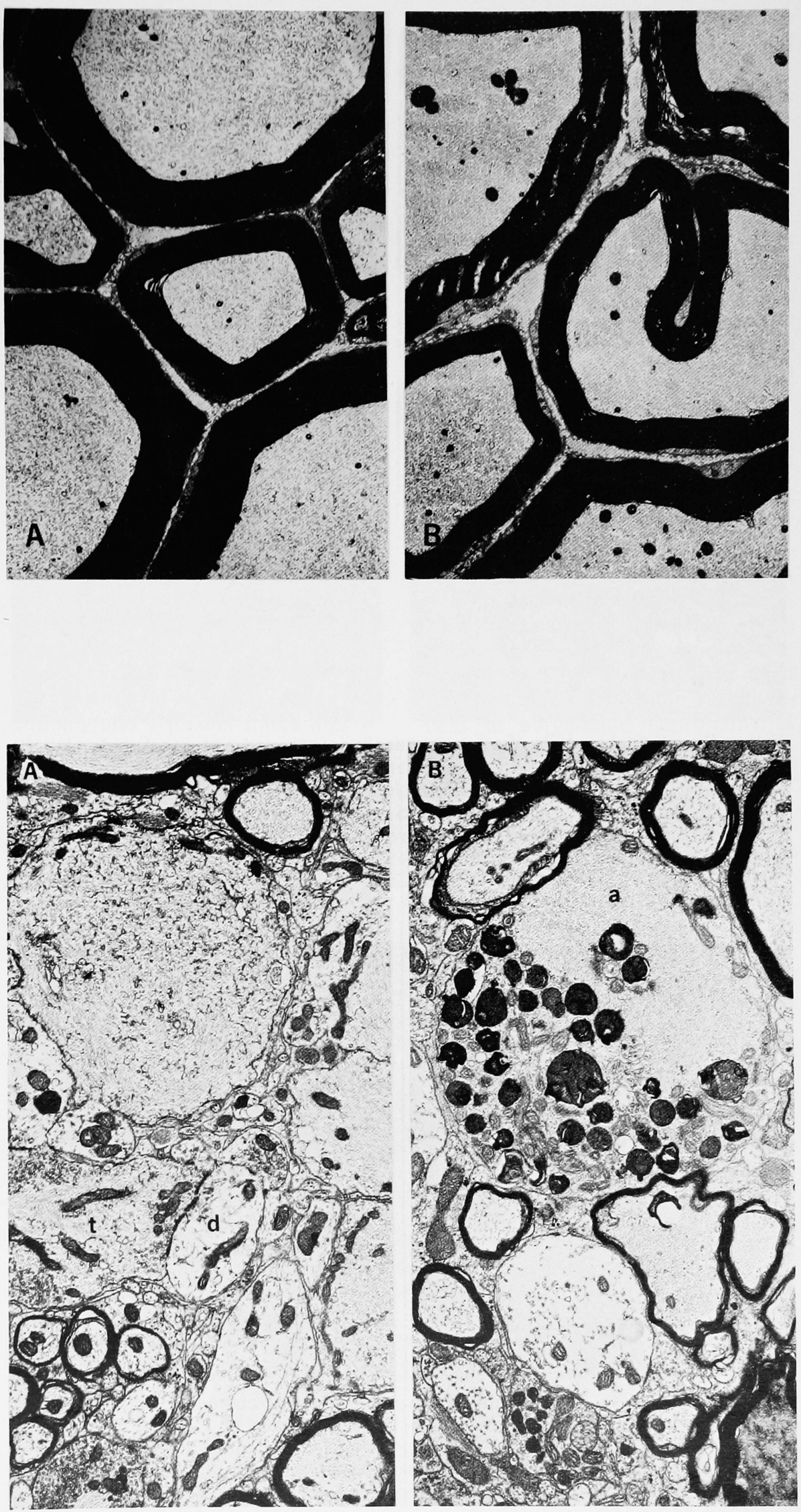
axon under the domain of each anterior horn cell perikaryon.

Current investigations of a nerve cell body metabolic disturbance, which precedes onset of distal ax- onal degeneration, are comparing neuron perikaryal amino acid uptake in normal and in intoxicated animals. Asbury and colleagues (1973) have reported evidence of a decreased
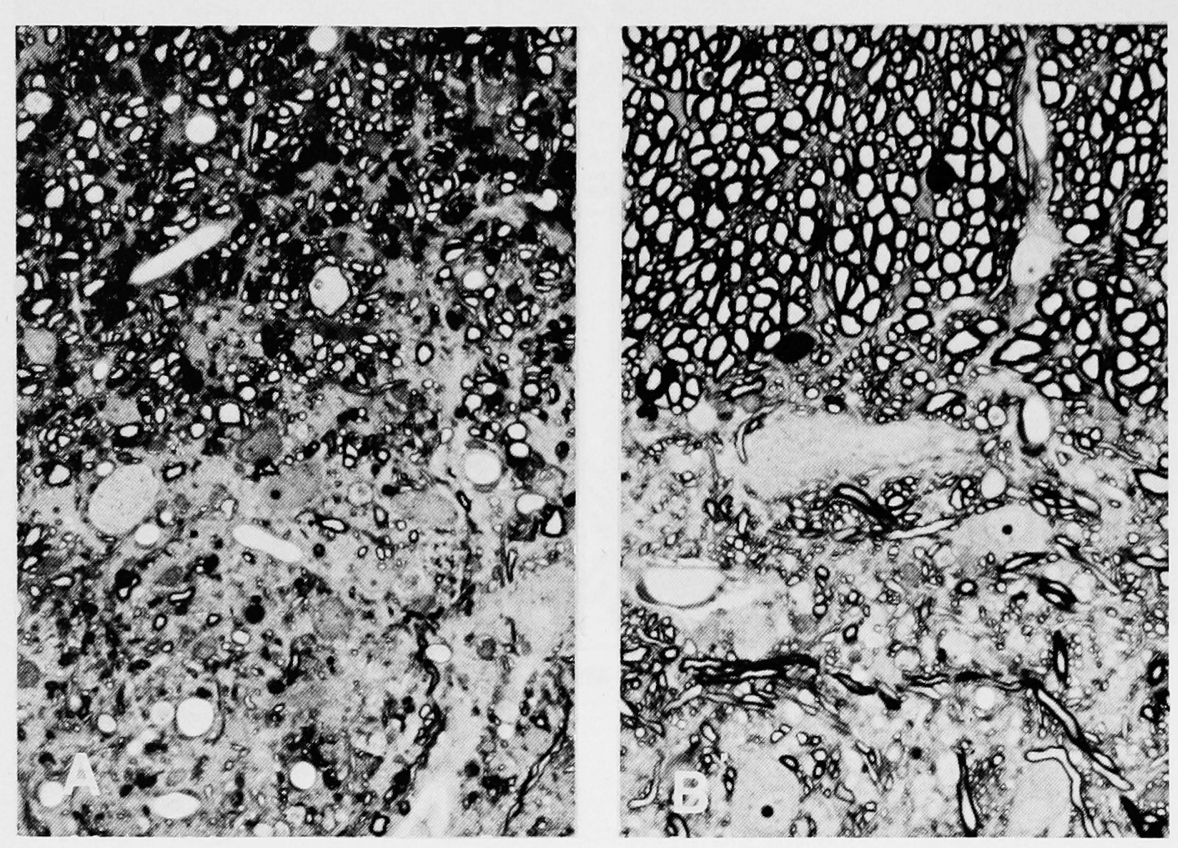

Figure 18 - Spinal medulla of a cat chronically intoxicated with acrylamide. A (left)

The gracile nucleus and tract show extensive fiber breakdown. X 350 .

$B$ (right). By contrast, the cuneate nucleus and tract in the same animal show no definite change. $1 \mu \mathrm{m}$ epon sections of tissue fixed with glutaraldehyde followed by osmium tetroxide and stained with methylene blue. X 350. (Figures 4 and 5, Prineas, 1969 b; reproduced by permission).

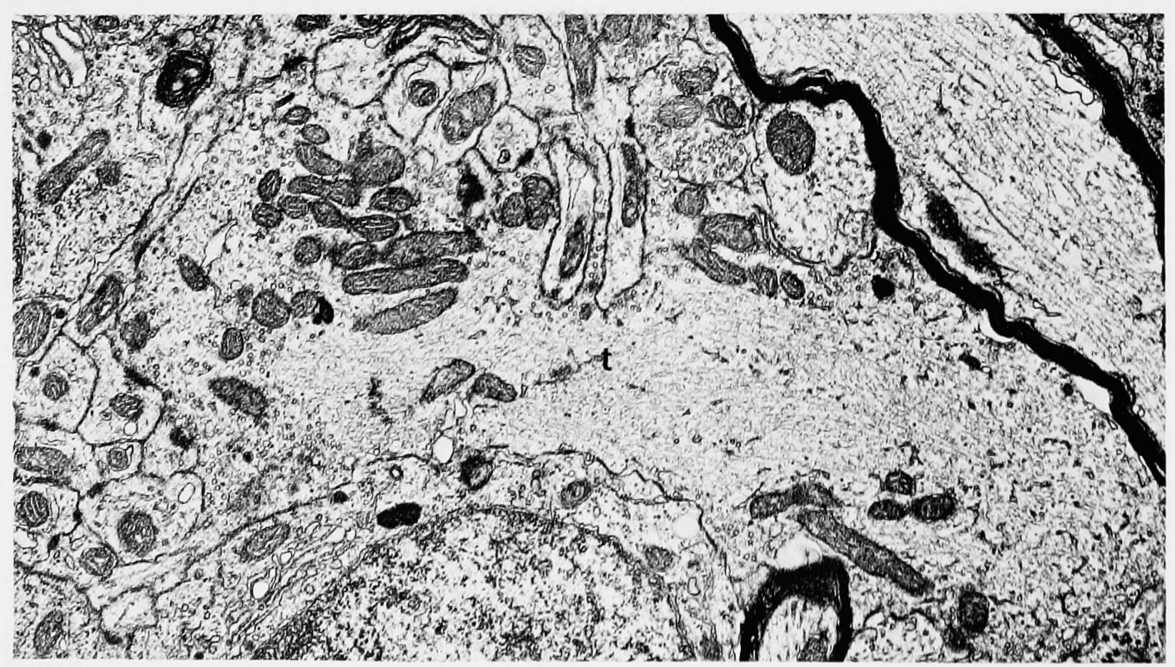

Figure 19 - Mossy fiber terminal (t) from the rostral cerebellar vermis of a cat intoxicated with $300 \mathrm{mg} / \mathrm{kg}$ of acrylamide over a period of 21 days. The terminal contains an abnormally large number of neurofilaments. X 13,000. Fixed in glutaraldehyde followed by osmium tetroxide; stained with uranyl acetate followed by lead citrate. (Courtesy of Dr. B. Ghetti). uptake of labeled leucine by anterior horn cells in mice prior to the appearance both of clinical signs and pathologic change in distal intramuscular nerve twigs. In another study, Hashimoto and Ando (1973) reported a normal in vitro uptake of labeled lysine and methionine by whole lumbo-sacral cord segments from intoxicated animals. Amino acid incorporation started to increase after the rats became paralysed and reached a maximum value after acrylamide was withdrawn.

Since some sensory nerve terminals (Pacinian corpuscles, primary terminals of muscle spindles) are especially vulnerable in acrylamide intoxicated cats, future studies might profitably examine dorsal root ganglia metabolism and correlate results with a simultaneous inspection of the fine structural integrity of these nerve terminals.

\section{ABNORMAL AXONAL TRANSPORT}

Another hypothesis to account for the dying-back pattern of axonal degeneration in acrylamide neuropathy assumes neuron perikaryal anabolism is unimpaired but that acrylamide interferes either with the mechanism by which materials are exported from the perikaryon, or with the axonal transport system by which materials are conveyed along the axon to distal sites of utilization. However, Cavanagh (1973) has suggested the very distal nature of axonal degeneration in acrylamide neuropathy would probably argue strongly against its being caused by a disturbance in the axonal transport system. It does seem likely a total breakdown in proximal $\rightarrow$ distal axonal transport would cause simultaneous proximal and distal axonal degeneration. However, it could also be argued that a partial, progressive impairment of axonal transport which resulted in decreasing amounts of material arriving per unit time at distal sites, might initially produce axonal compromise in those regions most removed from the source of supply. Impairment of axonal transport, either by a reduction in the transport velocity or in the 
volume transported, could account for distal axonal compromise: if the usual amount of normal material was transported at a reduced velocity, there would be a progressive increase in the delay of arrival of supplies with increasing distance from the neuron perikaryon. Alternatively, if less material was transported at a normal rate, and the proximal portion of the axon was supplied normally, then insufficient material might be available to maintain the distal axon normally. Thus, as with neuron perikaryal impairment, abnormal axonal transport would first jeopardize those axons with the greatest demand for perikaryal supplies.

In analyzing the theory of neuron perikaryal impairment, it was reasoned that dorsal root ganglion cells supplying Pacinian corpuscles, which have to maintain long peripheral and central axon branches, would be most susceptible to distal axonal degeneration since dwindling perikaryal supplies would be divided between each axon branch. In effect, therefore, the peripheral axon branch would suffer because of the presence of the central branch, and vice versa. By contrast, if acrylamide caused axonal transport system damage, leaving neuron perikaryal metabolism unimpaired, dorsal root ganglion cells presumably would supply the origin of each axon branch with a normal volume of material. In this situation, therefore, the presence of a long central axon branch should not affect the fate of the peripheral axon, since this would be solely determined by the degree of damage to its transport system. Thus, the theory of abnormal axonal transport would seem to predict that peripheral nerve fiber distal degeneration would occur in strict relationship to peripheral axonal volume. Since this prediction is discordant with the temporal pattern of nerve terminal degeneration in feline acrylamide neuropathy, it seems unlikely that abnormal axonal transport is solely responsible.

Two studies have examined the efficacy of axonal transport in cats intoxicated with acrylamide. By examining the movement of a peak of radioactivity, derived from the labeling of neuron perikaryal proteins with ${ }^{3} \mathrm{H}$-leucine, Pleasure and colleagues (1969) compared the slow component of axonal transport in dorsal and ventral roots of normal cats and cats with acrylamide neuropathy. The absence of slow axonal transport in most intoxicated animals was implicated as the possible cause for distal axonal degeneration. In a subsequent report, Bradley and Williams (1973) studied both the fast and slow components of axonal transport from dorsal root ganglia along the proximal regions of the sciatic nerve of cats with mild to moderate signs of peripheral neuropathy. Contrary to the findings of Pleasure et al., this study found no difference in slow axonal transport between acrylamide-intoxicated animals and controls. There was a decrease in the velocity of the crest of fast axon transport in the acrylamide-intoxicated cats, but Bradley and Williams stated this reduction was unlikely to be responsible for the distal fiber degeneration present in these animals.

It would be useful in future studies examining axonal transport in acrylamide-intoxicated animals to determine the temporal movement of radioactivity along the entire length of axon, including the sites of early terminal axon degeneration. For example, it might be feasible to compare the transport times of radioactive label from spinal ganglia to Pacinian corpuscles in the feet of normal and intoxicated animals, prior to the onset, and during early distal axonal degeneration.

\section{DIRECT AXONAL COMPROMISE}

Some recent ultrastructural observations of animals with experimental acrylamide neuropathy cannot be explained by either the theory of perikaryal insufficiency or axonal transport system damage. For example, since both of these theories predict that distal axonal changes would appear in longer fibers before shorter fibers of the same modality group, neither can account for the simultaneous axonal degeneration found in Pacinian corpuscles of forepaws and hindpaws of intoxicated cats (Schaumburg et al., 1974). Perhaps the major obstacle confronting both of these explanations of the dying-back process produced by acrylamide intoxication, is the observation that initial axonal pathology is multifocal and is not confined to the axonal extremity: i.e. when neurofilamentous change is seen in a sensory nerve terminal, paranodal neurofilamentous accumulations can be demonstrated on the same fiber in propinquity to the terminal, while concurrently, dorsal root axons display neurofilamentous hyperplasia and mitochondrial enlargement (Prineas, 1969b; Schaumburg et al., 1974).

It is possible to explain these observations by a third theory; that acrylamide might exert a direct, local toxic effect along the entire axon, other than by vitiating the axonal transport system. This third explanation of the dying-back process in acrylamide neuropathy is based on the assumption that the axon has vulnerabilities not shared by the perikaryon (Prineas, 1969a). If for example, acrylamide inactivated a substance (reacted with a protein?) in the axon which was required for normal axonal integrity, and the re-supply of this substance was dependent on perikaryal export, this alone could explain why the distal parts of neurons maintaining the greatest volume of axon degenerate first. In addition, a local toxic action of acrylamide on the axon might explain the pronounced nerve damage around blood vessels of systemically intoxicated rats (Suzuki and Pfaff, 1973). Moreover, since preterminal portions of Pacinian corpuscles are richly vascularized, the idea could also explain the simultaneous Pacinian corpuscle axon degeneration in fore and hindfeet of intoxicated cats (Schaumburg et al., 1974).

The demonstration that label from systemically-injected $\left({ }^{14} \mathrm{C}\right)$-acrylamide accumulates more in the distal half of the sciatic nerve than in the proximal half is compatible with 
this concept of a local toxic action of acrylamide (Ando and Hashimoto, 1972). In an elegant series of experiments, Ando (1973) has elucidated the mechanism responsible for this differential distribution of acrylamide. After a solution containing ${ }^{14} \mathrm{C}$-acrylamide and ${ }^{3} \mathrm{H}$-leucine was injected into the rat sacral canal, a large amount of the activity of both muclides was found in the proximal parts of the sciatic nerve. When the nerve was ligated at the level of the ischial tuberosity, $\left({ }^{3} \mathrm{H}\right)$ label, but not $\left.{ }^{14} \mathrm{C}\right)$ label, accumulated above the ligature, while in the peripheral parts of the sciatic nerve, $\left({ }^{14} \mathrm{C}\right)$ activity gradually increased with time. In conclusion, Ando stated that acrylamide seems to accumulate in nerves directly from the bloodstream.

\section{ACKNOWLEDGEMENTS}

The authors wish to thank Drs. B. Ghetti, A. Hopkins, J. Prineas, P. LeQuesne and K. Suzuki for generously contributing illustrations, Drs. N. M. Bikales, and A. Doyle for discussing parts of the manuscript, Drs. C. B. Shaffer and R. M. Clyne for releasing American Cyanamid Company memoranda, Drs. R. D. Terry and C. S. Raine for their help and encouragement, and Drs. A. Aguayo, A. Asbury, B. Ghetti, R. Kocen, D. Pleasure, W. Pryse-Phillips, A. Sumner and P. Thomas for their personal communications.

Supported in part by grants NS 03356 and NS 08952 from the National Institutes Health. Dr. Spencer is the recipient of a Joseph P. Kennedy, Jr., Fellowship in the Neurosciences.

\section{REFERENCES}

AGUAYO, A., PRYSE-PHILLIPS, W., (1974). Personal communication.

AMERICAN CYANAMID COMPANY (1952). New Products Bulletin, II collective, New York.

ANDO, K. (1973). Study on the transport of acrylamide to the peripheral part of the rat sciatic nerve. Proceedings of the Osaka Prefectural Institute of Public Health No. 11, 45-48, 1971.

ANDO, K. and HASHIMOTO, K. (1972). Accumulation of (14-C) acrylamide in mouse nerve tissue. Proceedings of the Osaka Prefectural Institute of Public Health No. 10, 7-12.

ASBURY, A. K., COX, S.C. and KANADA, D. (1973). ${ }^{3} \mathrm{H}$ leucine incorporation in acrylamide neuropathy in the mouse. Neurology 23, 406.

ASBURY, A. K., NIELSEN, S. L. TELFER, R. (1974). Glue sniffing neuropathy. Journal of Neuropathology and Experimental Neurology, 33, 191.
BARNES, J. M. (1969a). Toxic substances and the nervous system. Scientific Basis of Medicine Annual Reviews 183-201.

BARNES, J. M. (1969b). Toxic chemicals and peripheral neuropathy. Proceedings of the Royal Society of Medicine 62, 205-208. .

BARNES, J. M. (1970). Observations of the effects on rats of compounds related to acrylamide. British Journal of Industrial Medicine 27, 147-149.

BRADLEY, W. G. and ASBURY, A. K. (1970). Radioautographic studies of Schwann cell behavior. I. Acrylamide neuropathy in the mouse. Journal of Neuropathology and Experimental Neurology 29, 500-506.

BRADLEY, W. G. and WILLIAMS, M. H. (1973). Axoplasmic flow in axonal neuropathies - I. Axoplasmic flow in cats with toxic neuropathies. Brain 96, 235-246.

CAVANAGH, J. B. (1963). Organophosphorus neurotoxicity: a model "dying-back" process comparable to certain human neurological disorders. Guys Hospital Reports 112, 303-319.

CAVANAGH, J. B. (1964). The significance of the "dying-back" process in experimental and human neurological disease. International Review of Experimental Pathology 3, 219-267.

CAVANAGH, J. B. (1973). Peripheral neuropathy caused by chemical agents. CRC Critical Reviews in Toxicology 365-417.

CHENOWETH, M. B. (1955-1956). Personal communications quoted by A. S. Kuperman (1957).

DRUCKREY, H., CONSBRUCH, U. and SCHMÄHL, D. (1953). Effects of monomeric acrylamide on proteins. Zeitschrift für Naturforschung 86, 145-150.

FULLERTON, P. M. (1969). Electrophysiological and histological observations on peripheral nerves in acrylamide poisoning in man. Journal of Neurology, Neurosurgery and Psychiatry 32, 186-192.

FULLERTON. P. M. and BARNES, J. M. (1966). Peripheral neuropathy in rats produced by acrylamide. British Journal of Industrial Medicine 23, 210-221.

GHETTI, B. (1973). Personal communication.

GHETTI, B., WISNIEWSKI, H. M., COOK, R. D., and SCHAUMBURG, $\mathrm{H}$. H. (1973). Changes in the CNS after acute and chronic acrylamide intoxication. American Journal of Pathology 70, 78A.

GILLIATT, R. W. (1969). Experimental peripheral neuropathy. Scientific Basis of Medicine Annual Reviews 202-219.

HAMBLIN, D. O. (1956). The toxicity of acrylamide - a preliminary report. In: Hommage Au Doyen René Fabre, Membre De l'Institut, Professeur De Toxicologie A La Faculté De Pharmacie De Paris, 195-199, S.E.D.E.S. Paris

HASHIMOTO, K. and ALDRIDGE, W. N. (1970). Biochemical studies on acrylamide: a neurotoxic agent. Biochemical Pharmacology 19, 2591-2604.
HASHIMOTO, K. and ANDO, K. (1971). Studies on acrylamide neuropathy. Effects on the permeability of amino acid into nervous tissues, distribution and metabolism. Proceedings of the Osaka Prefectural Institute of Public Health 9, 1-4.

HASHIMOTO, K. and ANDO, K. (1973). Alteration of amino acid incorporation into proteins of the nervous system in vitro after administration of acrylamide to rats. Biochemical Pharmacology 22, 1057-1066.

HAZLETON, L. W. (1951-1953). Unpublished studies quoted by A. S. Kuperman (1957).

HOPKINS, A. P. (1968) Experimental neuropathy in the baboon. M.D. Thesis, University of London, London.

HOPKINS, A. P. (1970). The effects of acrylamide on the peripheral nervous system of the baboon. Journal of Neurology. Neurosurgery and Psychiatry 33, 805-816.

HOPKINS, A. P. and GILliATT, R. W. (1967). Acrylamide poisoning. British Medical Journal 4, 417.

HOPKINS, A. P. and GILLIATT, R. W. (1971). Motor and sensory conduction velocity in the baboon: normal values and changes during acrylamide neuropathy. Journal of Neurology, Neurosurgery and Psychiatry 34, 415-426.

HOPKINS, A. P. and LAMBERT, E. H. (1972). Conduction in unmyelinated fibers in experimental neuropathy. Journal of Neurology, Neurosurgery and Psychiatry 35, 163-169.

KAPLAN, M. L. and MURPHY, S. D. (1972a). Modification of acrylamide neuropathy in rats by various factors. Toxicology and Applied Pharmacology, 22, 302-303.

KAPLAN, M. L. and MURPHY, S. D. (1972b). Effect of acrylamide on rotarod performance and sciatic nerve $\beta$-glucuronidase activity of rats. Toxicology and Applied Pharmacology 22, 259-268.

KAPLAN, M. L., MURPHY, S. D. and GILLES, F. H. (1973). Modification of acrylamide neuropathy in rats by selected factors. Toxicology and Applied Pharmacology 24, 564-579.

KOCEN, R. S. and THOMAS, P. K. (1971). Personal communication.

KUPERMAN, A. S. (1955-56). Unpublished studies, quoted by A. S. Kuperman (1957).

KUPERMAN. A. S. (1957). The pharmacology of acrylamide. Ph.D. Thesis, Comell University, New York.

KUPERMAN, A. S. (1958). Effects of acrylamide on the central nervous system of the cat. Journal of Pharmacology and Experimental Therapeutics 123, 180-192.

LESWING, R. J. and RIBELIN, W. E. (1969). Physiologic and pathologic changes in acrylamide neuropathy. Archives of Environmental Health 18, 23-29.

McCOLLISTER, D. D., OYEN, F. and ROWE, V. K. (1964). Toxicology of acrylamide. Toxicology and Applied Pharmacology 6, 172-181. 
MORGAN-HUGHES, J. S., SINCLAIR, S. and THURSTON, J. H. J. (1974). The pattern of peripheral nerve regeneration induced by nerve crush in rats with severe acrylamide neuropathy. Brain 97, 215-232.

OCHOA, J. and MORGAN-HUGHES, J. A. (1974). Arrested peripheral nerve regeneration in acrylamide neuropathy. Proceedings VII International Congress of Neuropathology, Budapest.

PLEASURE, D. E., MISCHLER, K. D. ENGEL, W. K. (1969). Axonal transport of proteins in experimental neuropathies. Sciellce 166, 524-525.

PPINEAS, J. (1969a). The pathogenesis of dying-back polyneuropathies. I. An ultrastructural study of experimental triorthocresyl phosphate intoxication in the cat. Journal of Neuropathology and Experimental Neurology 28, 571-597.

PRINEAS, J. (1969b). The pathogenesis of dying-back polyneuropathies. II. An ultrastructural study of experimental acrylamide intoxication in the cat. Journal of Neuropathology and Experimental Neurology 28, 598-621.

RIBELIN, W. E. (1964). Acrylamide toxicity. Special studies conducted by the pathology group. American Cyanamid Company Internal Memorandum (quoted by permission).

RIKER, W. F. (1954). Summary of observations following single and repeated intravenous doses of acrylamide to cats. American Cyanamid Company Internal Memorandum (quoted by permission).
SCHA̧UMBURG, H. H., SPENCER, P.S., WISNIEWSKI, H., GHETTI, B. and COOK, R. D. (1973). Experimental acrylamide neuropathy - a light microscopic, ultrastructural and clinical study. Journal of Neuropathology and Experimental Neurology $32,171$.

SCHAUMBURG, H. H., WISNIEWSKI, H. and SPENCER, P. S. (1974). Ultrastructural studies of the dying-back process. I. Peripheral nerve terminal and axon degeneration in systemic acrylamide intoxication. Journal of Neuropathology and Experimental Neurology 33, 260-284.

SOLNITZSKY, O. (1953). Unpublished observations quoted by A.S. Kuperman (1957).

SPENCER, P.S. (1971). Light and electron microscopic observations on localised peripheral nerve injuries, 2 vols., Ph.D. Thesis, University of London, London.

SPENCER, P.S. and SCHAUMBURG, $H$. H. (1973). An ultrastructural study of the inner core of the Pacinian corpuscle. Journal of Neurocytology 2, 217-235.

SPENCER, P. S. and SCHAUMBURG, $H$. H. (1974). A review of acrylamide neurotoxicity, Part I. Properties, uses and human exposure. Canadian Journal of Neurological Sciences 1, 143-150.

SPENCER, P. S., SCHAUMBURG, H. H., RALEIGH, R. L. and TERHAAR, C. J. (1974). Nervous system degeneration produced by the industrial solvent methyl butyl ketone. Archives of Neurology, in press.
SPENCER, P. S. and THOMAS, P. K. Ultrastructural studies of the dying-back process. 2 . Schwann and oligodendroglial cell sequestration and removal of organelles for normal and diseased axons. Journal of Neurocytology, in press.

STOKINGER, H. E. (1956). In: Recent Industrial Hygiene Developments in the Field of Toxicology. American Industrial Hygiene Association Quarterly 17, 340-344.

SUMNER, A. J. and ASBURY, A. K. (1974). Acrylamide neuropathy: selective vulnerability of sensory fibers. Archives of Neurology 30, abstract.

SUZUKI, K. and De PAUL, L. (1971). Degeneration and regeneration of sciatic nerves in rats treated with acrylamide. Journal of Neuropathology and Experimental Neurology 32, 170.

SUZUKI, K. and PFAFF, L. (1973). Acrylamide neuropathy in rats. An electron microscopic study of degeneration and regeneration. Acta Neuropathologica 24, 197-213.

SWIFT, T. and LAMBERT, E. H. (1974). Quoted by M. Tsujihata et al. (1974).

TSUJIHATA, M., ENGEL, A. G. and LAMBERT, E. H. (1974). Neuromuscular junction ultrastructure in acrylamide "dying-back" neuropathy. A sequential morphometric study. Proceedings of the 26th annual meeting of the American Academy of Neurology, San Francisco.

WEST, R. (1959). American Cyanamid Company Interoffice Correspondence (quoted by permission). 